\title{
A Metagenomic-Based Approach for the Characterization of Bacterial Diversity Associated with Spontaneous Malolactic Fermentations in Wine
}

\author{
Carmen Berbegal ${ }^{1,2,+}$, Luigimaria Borruso ${ }^{3,+}$, Mariagiovanna Fragasso ${ }^{1}$, Maria Tufariello ${ }^{4}$, \\ Pasquale Russo ${ }^{1}$, Lorenzo Brusetti ${ }^{3}$, Giuseppe Spano ${ }^{1}$ and Vittorio Capozzi ${ }^{1, *(D)}$ \\ 1 Department of Agriculture, Food and Environment Sciences, University of Foggia, Via Napoli 25, \\ 71122 Foggia, Italy \\ 2 EnolabERI BioTecMed, Universitat de València, 46100 Valencia, Spain \\ 3 Faculty of Science and Technology, Free University of Bozen-Bolzano, 39100 Bozen-Bolzano, Italy \\ 4 Istituto di Scienze delle Produzioni Alimentari, Consiglio Nazionale delle Ricerche, Unità Operativa di \\ Supporto di Lecce, 73100 Lecce, Italy \\ * Correspondence: vittorio.capozzi@unifg.it; Tel.: +39-(0)881-589-303 \\ + These authors contributed equally to this work.
}

Received: 9 July 2019; Accepted: 13 August 2019; Published: 15 August 2019

\begin{abstract}
This study reports the first application of a next generation sequencing (NGS) analysis. The analysis was designed to monitor the effect of the management of microbial resources associated with alcoholic fermentation on spontaneous malolactic consortium. Together with the analysis of 16S rRNA genes from the metagenome, we monitored the principal parameters linked to MLF (e.g., malic and lactic acid concentration, $\mathrm{pH}$ ). We encompass seven dissimilar concrete practices to manage microorganisms associated with alcoholic fermentation: Un-inoculated must (UM), pied-de-cuve (PdC), Saccharomyces cerevisiae (SC), S. cerevisiae and Torulaspora delbrueckii co-inoculated and sequentially inoculated, as well as S. cerevisiae and Metschnikowia pulcherrima co-inoculated and sequentially inoculated. Surprisingly, each experimental modes led to different taxonomic composition of the bacterial communities of the malolactic consortia, in terms of prokaryotic phyla and genera. Our findings indicated that, uncontrolled AF (UM, PdC) led to heterogeneous consortia associated with MLF (with a relevant presence of the genera Acetobacter and Gluconobacter), when compared with controlled AF (SC) (showing a clear dominance of the genus Oenococcus). Effectively, the SC trial malic acid was completely degraded in about two weeks after the end of AF, while, on the contrary, malic acid decarboxylation remained uncomplete after 7 weeks in the case of UM and PdC. In addition, for the first time, we demonstrated that both (i) the inoculation of different non-Saccharomyces (T. delbrueckii and M. pulcherrima) and, (ii) the inoculation time of the non-Saccharomyces with respect to $S$. cerevisiae resources (co-inoculated and sequentially inoculated) influence the composition of the connected MLF consortia, modulating MLF performance. Finally, we demonstrated the first findings of delayed and inhibited MLF when M. pulcherrima, and T. delbrueckii were inoculated, respectively. In addition, as a further control test, we also assessed the effect of the inoculation with Oenococcus oeni and Lactobacillus plantarum at the end of alcoholic fermentation, as MLF starter cultures. Our study suggests the potential interest in the application of NGS analysis, to monitor the effect of alcoholic fermentation on the spontaneous malolactic consortium, in relation to wine.
\end{abstract}

Keywords: wine; malolactic fermentation; lactic acid bacteria; 16S rRNA metataxonomy; Saccharomyces cerevisiae; Oenococcus oeni; Lactobacillus plantarum; Metschnikowia pulcherrima; Torulaspora delbrueckii; malolactic consortium 


\section{Introduction}

Wine is a complex hydro-alcoholic chemical mixture obtained via microbial-based bio-conversions of grape juice. A heterogeneous microbiota including, yeasts, bacteria, and filamentous fungi evolve from grape crushing up to the bottle, throughout oenological fermentations and processes [1]. Among the different microorganism, yeast has a predominant role in the metabolism of grape juice, which leads to the production of ethanol, and of other metabolites susceptible to influencing wine acceptance and quality, during the 'alcoholic fermentation' (AF) phase [2,3]. After the efficient development of yeasts, grape juice is converted to wine. A secondary desired microbial-driven process, the 'malolactic fermentation' (MLF), can take place in the must-wine system and mainly consists of the decarboxylation of malic acid in lactic acid performed by lactic acid bacteria (LAB) [4]. Also in this case, the microbial development is connected with the release of other metabolites, which are able to affect wine quality [5]. The model microorganisms for alcoholic and malolactic fermentation are, Saccharomyces cerevisiae, and Oenococcus oeni, respectively. The strains belonging to these two species have been selected to design starter cultures, which are useful for promoting AF and MLF in the wine sector [6-8]. However, a spontaneous consortium of microorganism is also associated with the matrix (grapes, must, and wine), and has been recently explored and characterized, in order to investigate their positive and negative roles, relating to specific oenological production [9-12]. With this concern in mind, in the last years, an increased interest has been raised in selecting species/strains belonging to the so-called non-Saccharomyces yeast species [13-16]. This attentiveness is attributable to the potential application of these resources to improve quality and/or safety of wine, and to the renovated interest in the study of microbial diversity connected with productions of specific terroir and susceptible to the influence peculiar organoleptic traits of regional wines [17-19]. A certain number of non-Saccharomyces strains have been already characterized and used to formulate commercial microbial preparations [8]. These starter cultures are often used in association with classical starter cultures to induce AF (i.e., S. cerevisiae) thereby diversifying wine production. Non-Saccharomyces species/strains are generally less adapted than S. cerevisiae to perform alcoholic fermentation, thus the management of these resources in enology foresee the use of a) co-inoculation with an increased concentration of the non-Saccharomyces or, $b$ ) a sequential inoculation with a preliminary inoculation of non-Saccharomyces $[18,20,21]$. While the reciprocal interactions among $S$. cerevisiae and the different non-Saccharomyces species/strains are explored [1,22,23], as well as the relationship among S. cerevisiae and the different bacteria connected to MLF $[1,24,25]$, little is known about the impact of the use of non-Saccharomyces on the bacterial diversity belonging to the malolactic consortium and on the efficacy of malolactic fermentation [26-29]. Newly-developed sequencing strategies, usually known as next generation sequencing (NGS) techniques, involve versatile applications in the field of food microbiology, providing interesting insights in the study of microbiota related to food fermentation [30]. Among the other interesting application, NGS technique allowed advances into the description of bacterial diversity connected with wine-related environments $[29,31]$. In the last eight years, several investigations delved into prokaryotic diversity associated with grapes, grape musts, and/or grape wines (Table 1).

Table 1. List of studies on bacterial diversity associated with grapes and/or musts and/or wines.

\begin{tabular}{ccc}
\hline Year & Subject & References \\
\hline 2011 & $\begin{array}{c}\text { Study of bacterial communities associated with the leaf and } \\
\text { berry surfaces of 'Chardonnay' grape }\end{array}$ & [32] \\
\hline 2012 & $\begin{array}{c}\text { Study of bacterial communities associated with botrytized wine } \\
\text { fermentations (sampling time compatible with MLF) }\end{array}$ & [33] \\
\hline 2014 & Grape-associated microbial biogeography from different regions \\
of California
\end{tabular}


Table 1. Cont.

\begin{tabular}{|c|c|c|}
\hline Year & Subject & References \\
\hline 2015 & $\begin{array}{l}\text { Study of bacterial communities associated with spontaneous } \\
\text { wine fermentations (from six Portuguese wine appellations) in } \\
\text { the initial musts, start and end of alcoholic fermentation }\end{array}$ & [35] \\
\hline 2015 & $\begin{array}{c}\text { Influence of the use of sulfur dioxide (in winemaking) on } \\
\text { bacterial diversity }\end{array}$ & [36] \\
\hline 2015 & $\begin{array}{l}\text { Study of the evolution of bacterial communities during the } \\
\text { alcoholic fermentation of organically and conventionally } \\
\text { produced wines }\end{array}$ & [37] \\
\hline 2016 & $\begin{array}{l}\text { Study of the bacterial communities associated with the main } \\
\text { wine fermentation stages including malolactic fermentation }\end{array}$ & [38] \\
\hline 2016 & $\begin{array}{c}\text { Study of the bacterial communities in berries, musts, and wines, } \\
\text { including malolactic fermentation }\end{array}$ & [39] \\
\hline 2016 & $\begin{array}{l}\text { Study of the bacterial communities associated with Corvina } \\
\text { berries at the end of the withering process performed in two } \\
\text { different conditions }\end{array}$ & [40] \\
\hline 2018 & $\begin{array}{l}\text { Correlation between soil- and grape-associated bacterial } \\
\text { communities in vineyards }\end{array}$ & [41] \\
\hline 2018 & $\begin{array}{l}\text { Study of bacterial diversity associated with healthy, rotten, } \\
\text { botrytized grapes and with the derived musts and wine (up to } \\
\text { the alcoholic fermentation) }\end{array}$ & [42] \\
\hline 2018 & $\begin{array}{l}\text { Study of the epiphytic bacterial community of vine bark and its } \\
\text { relationships with grape bacterial diversity }\end{array}$ & [43] \\
\hline 2019 & $\begin{array}{l}\text { Study of bacterial diversity associated with the grape surface of } \\
\text { samples collected from different wine regions in Xinjiang, China }\end{array}$ & [44] \\
\hline 2019 & $\begin{array}{l}\text { Bacterial communities associated with alcoholic fermentation, } \\
\text { including the variation between musts that successfully } \\
\text { complete alcoholic fermentation and those that become 'stuck' } \\
\text { in the process }\end{array}$ & [45] \\
\hline
\end{tabular}

The widest part of these dealt with bacterial diversity on grapevines (Table 1) [32,34,40,41,43, 44]. Some studies followed the evolution of bacterial communities up to the end of alcoholic fermentation [35-37,42,45]. Few works investigated the prokaryotic microbiota, associated with malolactic fermentation of wine $[33,38,39]$ using NGS analysis, the biotechnological phase of the major positive impact of bacteria on wine quality [4]. Only in one case, in botrytized wine, the effect of spontaneous versus inoculated (S. cerevisiae biomass) alcoholic fermentation on the malolactic consortium was evaluated [33].

In this short communication, for the first time, we propose NGS analysis as a tool to monitor the effect of the varying ways to manage microbial resources associated with alcoholic fermentation on the spontaneous malolactic consortium, an issue that has attracted significant interest to ensure the quality and safety of wine fermentation. For the assessment of the performance, and of the bacterial diversity associated with the spontaneous malolactic consortium, we monitored the principal parameters of MLF (e.g., malic acid concentration, $\mathrm{pH}$ ); and performed a phylogenetic analysis, based on 16S rRNA genes from the metagenome. Together with the simplest inoculated trial (S. cerevisiae biomass), we tested two cases of exploitations of indigenous yeast consortia corresponding to uninoculated must and on the practice of 'pied-de-cuve' in order to understand the influence of the different uses of microbial resources on malolactic fermentation. Considering the increasing interest in the use of selected non-Saccharomyces strains, our focus was on the use of non-Saccharomyces (Metschnikowia pulcherrima and Torulaspora delbrueckii) coupled with S. cerevisiae yeasts, using two different inoculation times (co-inoculation and sequential inoculation within one day). Finally, as a sort of further control trial, we compared these trials with the effect of adding starter cultures for MLF (i.e., Oenococcus oeni, Lactobacillus plantarum) at the end of alcohol fermentation. 


\section{Results}

This paper reports the original findings of metagenomic-based approaches for the characterization of bacterial diversity associated with spontaneous malolactic fermentation in wine, integrated with some information about the classical monitoring of malolactic fermentation. The monitoring of the spontaneous malolactic consortium has been evaluated in relation to different uses of microbial resources, associated with the development of alcoholic fermentation in wine. In saying that, we also tested the use of bacterial starter cultures, that have been tailored to promote malolactic fermentation.

\subsection{Experimental Modes and Monitoring of Malolactic Fermentation}

The proposed experimental plan investigated the different ways to manage microbial resources associated with the alcoholic fermentation (Table 2; PdC, UM, SC, SCMPco, SCTDco, SCMPsq, and SCTDsq). The basic un-inoculation of the grape must (that means to rely on the spontaneous presence of indigenous yeasts) was compared with the practice of pied-de-cuve. Pied-de-cuve consists of the inoculation with a small amount of must, that was already undergoing spontaneous alcoholic fermentation [46] in a sort of microbial pre-enrichment practice. Hence, the fermentative process relies on the spontaneous presence of indigenous 'enriched' yeast. In all of the other experimental trials, the biomass of a single isolate from a commercial starter culture of $S$. cerevisiae was inoculated. In two experimental modes, this strain was combined with the biomass of a single isolate from a commercial starter culture of $M$. pulcherrima, using a co-inoculation and a sequential inoculation approach. In two other similar experimental modes, the S. cerevisiae strain was combined with the biomass of a single isolate from a commercial starter culture of T. delbrueckii, using co-inoculation and sequential inoculation methods. Finally, after $S$. cerevisiae development, in two trials, the biomass of single isolates from commercial starter cultures of $O$. oeni and of L. plantarum were inoculated separately, at the end of alcoholic fermentation (Table 2; SCOO, SCLP).

Table 2. List of the experimental modes tested in our experimental plan. Each microbial management explored has been tested in three independent biological replicates.

\begin{tabular}{cc}
\hline Codes & Tested Management of The Microbial Resources \\
\hline PdC & 'Pied-de-cuve' practice \\
UM & Uninoculated must \\
SC & S. cerevisiae \\
SCMPco & S. cerevisiae + M. pulcherrima $(\mathrm{co})$ \\
SCTDco & S. cerevisiae + T. delbrueckii $(\mathrm{co})$ \\
SCOO & S. cerevisiae + O. oeni \\
SCLP & S. cerevisiae + L. plantarum \\
SCMPsq & S. cerevisiae + M. pulcherrima $(\mathrm{sq})$ \\
SCTDsq & S. cerevisiae + T. delbrueckii $(\mathrm{sq})$ \\
\hline
\end{tabular}

co: co-inoculated; sq: sequentially inoculated.

In all the trials, total yeast counts were generally similar during alcoholic fermentation (Figure 1). The reduction of viable yeasts coincides with the third week after starting AF. Although, a more rapid decrease was noted in the samples where the malolactic fermentation started quickly.

The LAB count highlighted a considerable presence of malolactic bacteria associated with the samples, where a rapid malolactic fermentation was observed (SC, SCOO) (Figure 2). After inoculation of L. plantarum cells, viable bacteria was shown to slow down about ten-fold, and then raised to a concentration slightly higher than the inoculated one. The inoculation of M. pulcherrima led to a delay in the growth of LAB; in fact, only at the last sampling point (56th day), we found a concentration higher than $1 \times 10^{7} \mathrm{CFU} / \mathrm{mL}$, after a long latency at a concentration around $1 \times 10^{4} \mathrm{CFU} / \mathrm{mL}$ and $1 \times 10^{3}$ $\mathrm{CFU} / \mathrm{mL}$ in the case of co-inoculation (SCMPco), and of sequential inoculation (SCMPsq), respectively. 
In the remaining fermentation trials (PdC, UM, SCTDco, SCTDsq), the LAB population decreased to less than $1 \times 10^{2} \mathrm{CFU} / \mathrm{mL}$ after 38 days of incubation.

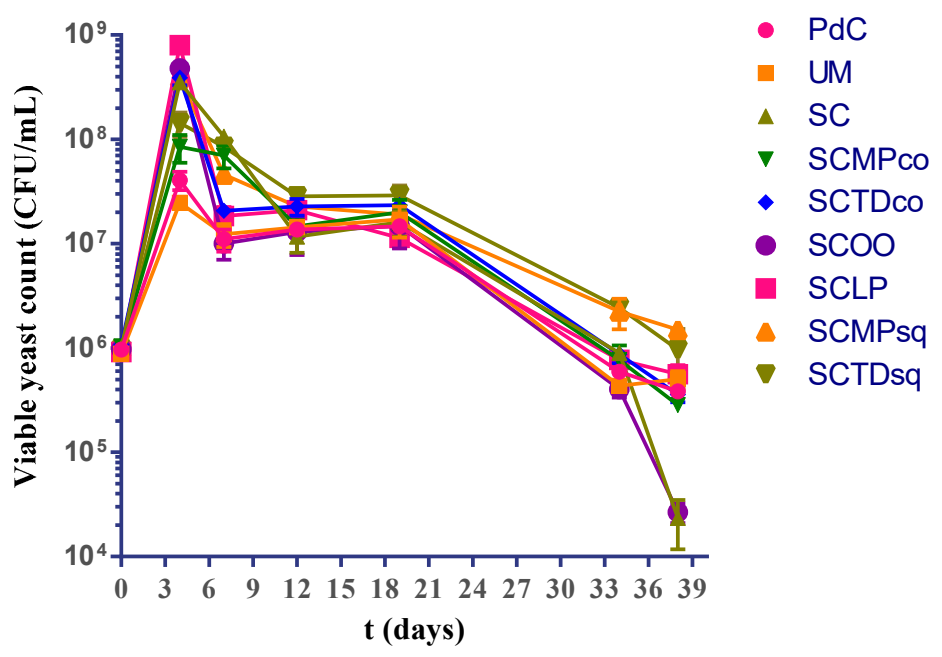

Figure 1. Variations of viable yeast during the vinification process in the different explored experimental modes: PdC: 'Pied-de-cuve'; UM: Uninoculated must; SC: S. cerevisiae; SCMPco: S. cerevisiae + M. pulcherrima (co-inoculated); SCTDco: S. cerevisiae + T. delbrueckii (co-inoculated); SCOO: S. cerevisiae + O. oeni; SCLP: S. cerevisiae + L. plantarum; SCMPsq: S. cerevisiae + M. pulcherrima (sequentially inoculated); SCTDsq: S. cerevisiae + T. delbrueckii (sequentially inoculated). After 12 days of yeasts inoculation, biomass of $O$. oeni and L. plantarum has been added for the induction of malolactic fermentation in the trials SCOO and SCLP, respectively. The data shown are an average of three independent experiments.

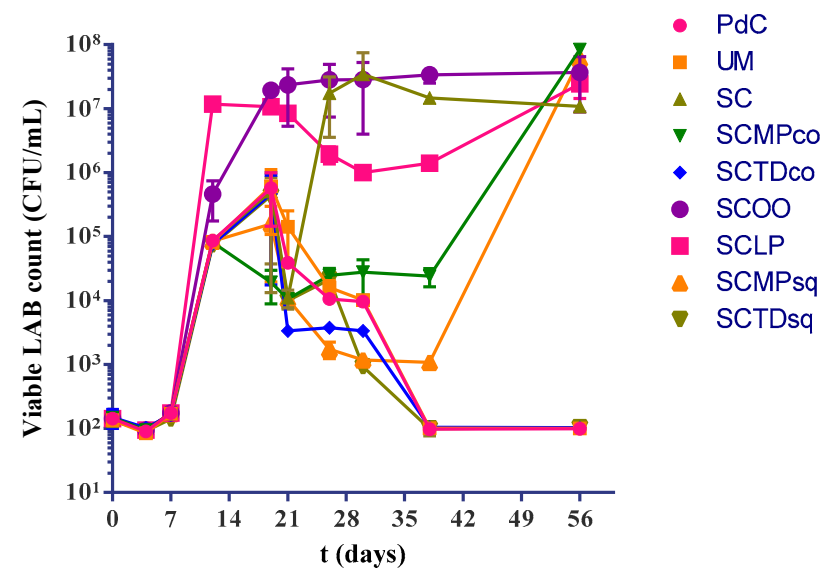

Figure 2. Variations of viable lactic acid bacteria during the vinification process in the different explored experimental modes: PdC: 'Pied-de-cuve'; UM: Uninoculated must; SC: S. cerevisiae; SCMPco: S. cerevisiae + M. pulcherrima (co-inoculated); SCTDco: S. cerevisiae + T. delbrueckii (co-inoculated); SCOO: S. cerevisiae + O. oeni; SCLP: S. cerevisiae + L. plantarum; SCMPsq: S. cerevisiae + M. pulcherrima (sequentially inoculated); SCTDsq: S. cerevisiae + T. delbrueckii (sequentially inoculated). After 12 days of yeasts inoculation, biomass of $O$. oeni and L. plantarum was added for the induction of malolactic fermentation in the trials SCOO, and SCLP, respectively. The data shown are an average of three independent experiments.

Our findings highlighted complete malolactic fermentation after about three weeks (less than 2 weeks after the inoculation) when samples were inoculated with O. oeni after alcoholic fermentation (Figure 3). Moreover, the simple inoculation with S. cerevisiae alone led to a good performance of MLF (closed in little bit more than 2 weeks after the end of AF), while, the combination SCLP 
reduced the malic acid concentration to about $1 \mathrm{~g} / \mathrm{L}$ in 2 weeks after inoculation. There was complete malic acid degradation in about 6 weeks after the end of the AF. In the samples inoculated with M. pulcherrima (i) MLF proceeded really slowly up to the fourth week after the end of AF, and (ii) a late but complete malolactic fermentation was observed (about 6 weeks after the AF). In contrast, an incomplete degradation of malic acid was observed in the remaining trials (UM, PdC, SCTDco, SCTDsq).

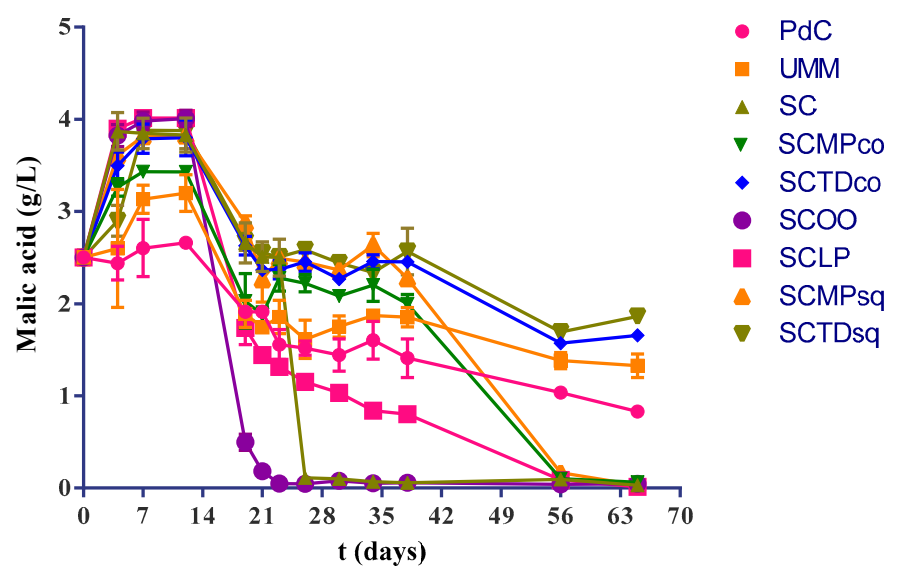

Figure 3. Malic acid concentration trends during the vinification process in the different explored experimental modes: PdC: 'Pied-de-cuve'; UM: Uninoculated must; SC: S. cerevisiae; SCMPco: S. cerevisiae + M. pulcherrima (co-inoculated); SCTDco: S. cerevisiae + T. delbrueckii (co-inoculated); SCOO: S. cerevisiae + O. oeni; SCLP: S. cerevisiae + L. plantarum; SCMPsq: S. cerevisiae + M. pulcherrima (sequentially inoculated); SCTDsq: S. cerevisiae $+T$. delbrueckii (sequentially inoculated). After 12 days of yeasts inoculation, biomass of $O$. oeni and L. plantarum has been added for the induction of malolactic fermentation in the trials SCOO, and SCLP, respectively. In all the other experimental modes wines undergo spontaneous malolactic fermentation. The data shown are an average of three independent experiments.

Lactic acid productions was generally found symmetrical to the reported kinetics of malic acid degradation (Figure 4).

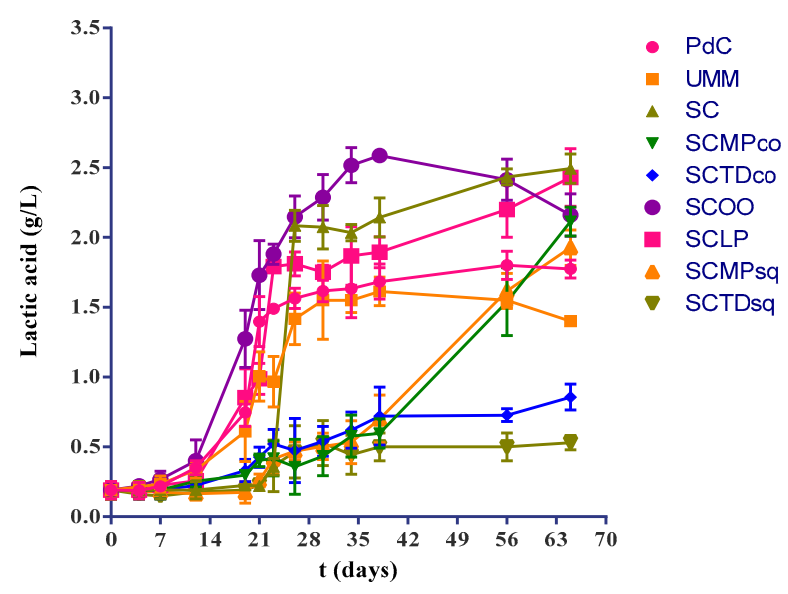

Figure 4. Lactic acid concentration trends during the vinification process in the different explored experimental modes: PdC: 'Pied-de-cuve'; UM: Uninoculated must; SC: S. cerevisiae; SCMPco: S. cerevisiae + M. pulcherrima (co-inoculated); SCTDco: S. cerevisiae + T. delbrueckii (co-inoculated); SCOO: S. cerevisiae + O. oeni; SCLP: S. cerevisiae + L. plantarum; SCMPsq: S. cerevisiae + M. pulcherrima (sequentially inoculated); SCTDsq: S. cerevisiae $+T$. delbrueckii (sequentially inoculated). After 12 days of yeasts inoculation, biomass of O. oeni and L. plantarum has been added for the induction of malolactic fermentation in the trials SCOO, and SCLP, respectively. The monitoring started with the beginning of malolactic fermentation. The data shown are an average of three independent experiments. 
The comparison of the malic and lactic acid concentrations at the end-point (65 days, about 7 weeks after the end of AF) allowed us to highlight better the significant differences in the malolactic performances associated with the tested uses of the microbial resources (Table 3). The inoculation of S. cerevisiae is associated with an efficient consumption of malic acid. In contrast, the un-inoculated experimental modes (PdC, UM) led to consistent residual concentrations of L-malic acid $(0.830 \mathrm{~g} / \mathrm{L}$, and $1.327 \mathrm{~g} / \mathrm{L}$ respectively), even if we depicted a significantly better malic decarboxylation in the case of PdC management. With regard to non-Saccharomyces employment, the use of M. pulcherrima was found related with efficient malolactic fermentative performances, while inoculated T. delbrueckii cells resulted in unsatisfying levels of L-malic contents. Furthermore, in the case of T. delbrueckii addition, we can underline a slight, but significant difference between reached levels in L-malic content, in the case of co-inoculation and sequential inoculation with S. cerevisiae $(1.657 \mathrm{~g} / \mathrm{L}$ and $1.863 \mathrm{~g} / \mathrm{L})$.

Table 3. L-malic acid and lactic acid concentration at the end of the vinification process (day 65) in the different explored experimental modes. Results of ANOVA analysis are shown as letters (a-f) on the corresponding data.

\begin{tabular}{ccc}
\hline & L-malic Acid $(g / L)$ & Lactic Acid $(g / L)$ \\
\hline PdC & $0.830 \pm 0.052^{\mathrm{a}}$ & $1.773 \pm 0.064^{\mathrm{a}}$ \\
UM & $1.327 \pm 0.127^{\mathrm{b}}$ & $1.400 \pm 0.001^{\mathrm{b}}$ \\
SC & $0.030 \pm 0.017^{\mathrm{c}}$ & $2.493 \pm 0.105^{\mathrm{c}}$ \\
SCMPco & $0.062 \pm 0.032^{\mathrm{c}}$ & $2.113 \pm 0.102^{\mathrm{d}}$ \\
SCTDco & $1.657 \pm 0.021^{\mathrm{d}}$ & $0.857 \pm 0.093^{\mathrm{e}}$ \\
SCOO & $0.046 \pm 0.020^{\mathrm{c}}$ & $2.160 \pm 0.151^{\mathrm{d}}$ \\
SCLP & $0.013 \pm 0.005^{\mathrm{c}}$ & $2.430 \pm 0.206^{\mathrm{cd}}$ \\
SCMPsq & $0.300 \pm 0.017^{\mathrm{c}}$ & $1.927 \pm 0.127^{\mathrm{ad}}$ \\
SCTDsq & $1.863 \pm 0.025^{\mathrm{e}}$ & $0.530 \pm 0.005^{\mathrm{f}}$ \\
\hline
\end{tabular}

We conducted the experiment using a must from the Apulian region (Southern Italy) characterized by a $\mathrm{pH}$ of about 3.8. This high $\mathrm{pH}$ is typical of hot climate zones of the Mediterranean area, and it is also representative of the possible chemical characteristics of grape must from other regions, related to global warming [47]. Considering the experimental findings, a slight deacidification, corresponding to a $\mathrm{pH}$ increase of about 0.2 , was observed in the experimental modes SC, SCMPco, SCOO, SCLP, and SCMPsq (Figure 5). In contrast, only minor changes were found in trials PdC, UM, SCTDco, and SCTDsq. An increase of $\mathrm{pH}$ was firstly noted in the sample inoculated with O. oeni.

\subsection{Malolactic Consortia Monitored using 165 High Throughput Sequencing}

The analysis of $16 \mathrm{~S}$ metagenomics was performed in all the experimental modes (Table 2) after 30 days of grape crushing, and the beginning of alcoholic fermentation during the MLF. Hence, the results provide 'snapshot' of the malolactic consortia after 30 days. This time had been chosen on the basis of, malic acid consumed, and lactic acid produced, as reported in Figures 2 and 3, respectively. Moreover, the average time, reasonable for a spontaneous MLF in wineries, has been considered [48]. We waited a few days after that the first spontaneous MLF consortium completed malic acid degradation, remaining within the 3 weeks that are generally recognized as the average time for a spontaneous MLF in oenology. The bacterial diversity, associated with the malolactic consortia of the different experimental modes, was described by $16 \mathrm{~S}$ rRNA gene metagenetic analysis. We obtained a total of 3,045,338 high-quality sequences of $16 \mathrm{~S}$ rRNA, with an average of $88,376 \pm 32,615$ reads per sample. The total number of Operational Units (OTUs) was 17,540 with an average of $2573 \pm 792$ (Table S1).

Chao1 and Shannon indices (Figures 6 and 7) were calculated for all the metagenomic malolactic consortia associated with the tested management of the microbial resources (Table 1). On the one hand, we report the calculation of the non-parametric richness estimator Chao1. On the other, we propose the values of Shannon's diversity index that provide a measure of both richness and dominance. 


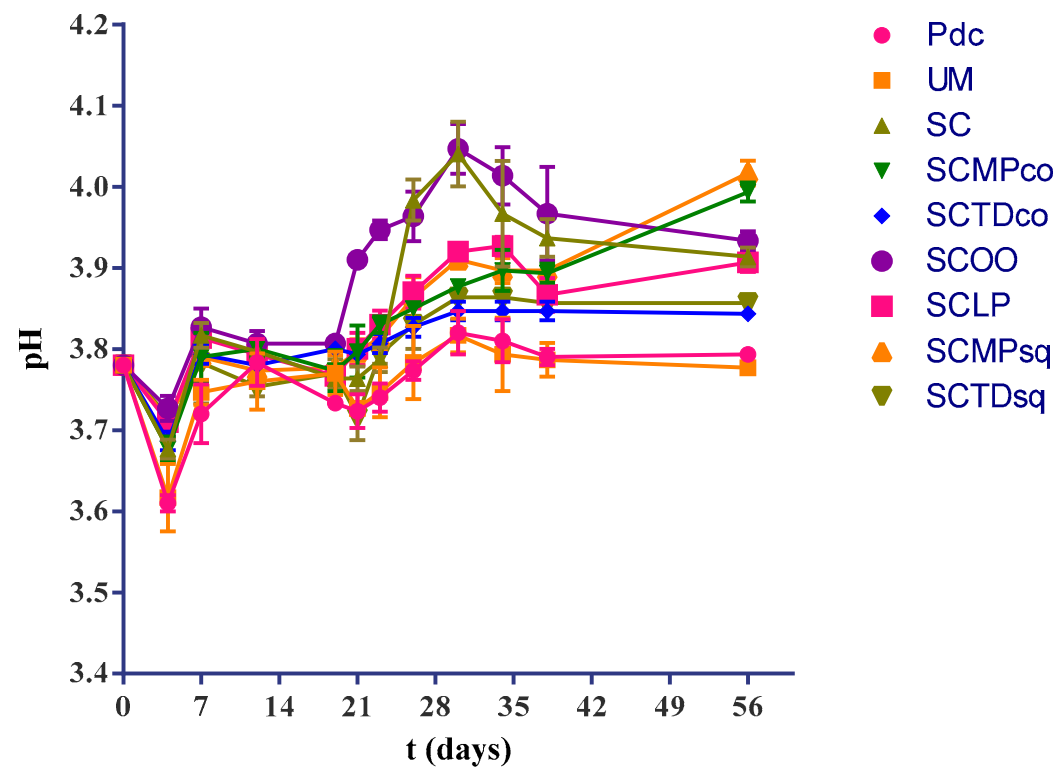

Figure 5. $\mathrm{pH}$ changes associated with the vinification process in the different explored experimental modes: PdC: 'Pied-de-cuve'; UM: Uninoculated must; SC: S. cerevisiae; SCMPco: S. cerevisiae + M. pulcherrima (co-inoculated); SCTDco: S. cerevisiae + T. delbrueckii (co-inoculated); SCOO: S. cerevisiae + O. oeni; SCLP: S. cerevisiae + L. plantarum; SCMPsq: S. cerevisiae + M. pulcherrima (sequentially inoculated); SCTDsq: S. cerevisiae $+T$. delbrueckii (sequentially inoculated). After 12 days of yeasts inoculation, biomass of $O$. oeni and L. plantarum were added for the induction of malolactic fermentation in the trials SCOO, and SCLP, respectively. In all the other experimental modes, wine underwent spontaneous malolactic fermentation. The data shown are an average of three independent experiments.

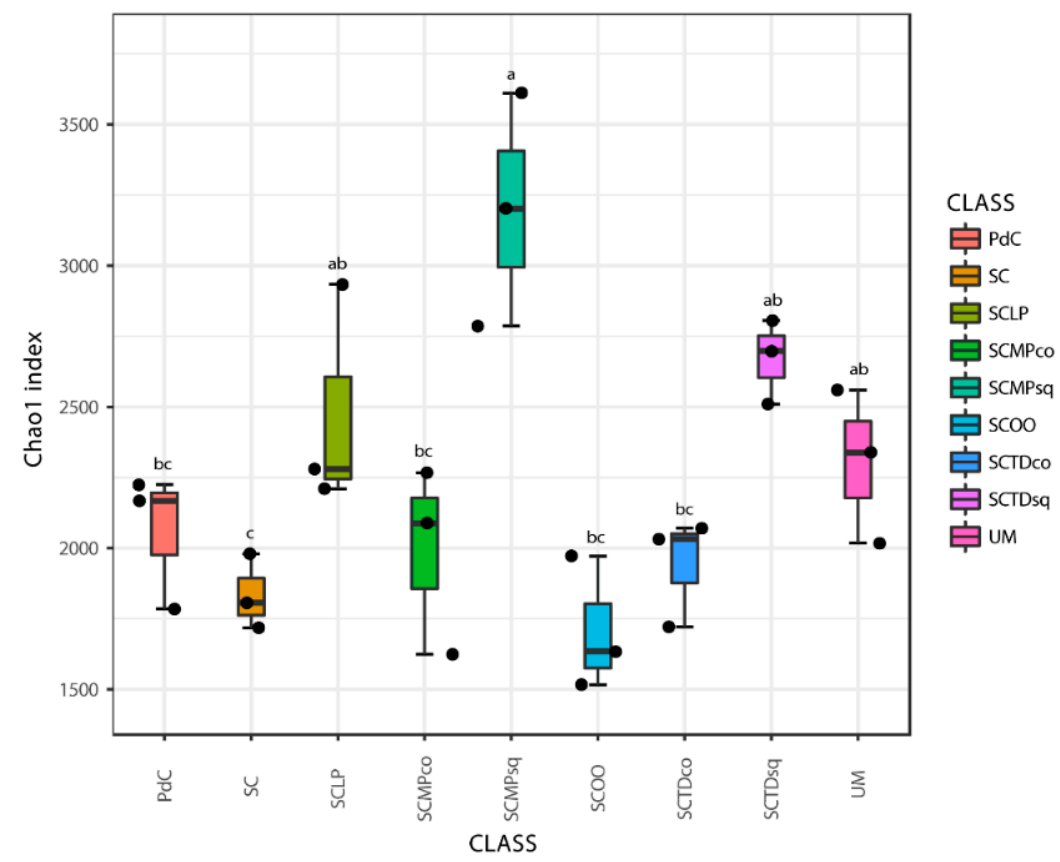

Figure 6. Alpha-Diversity estimates based on OTU-data with Chao1 indices for the experimental modes tested. Results of ANOVA analysis are shown as letters on the corresponding data. 


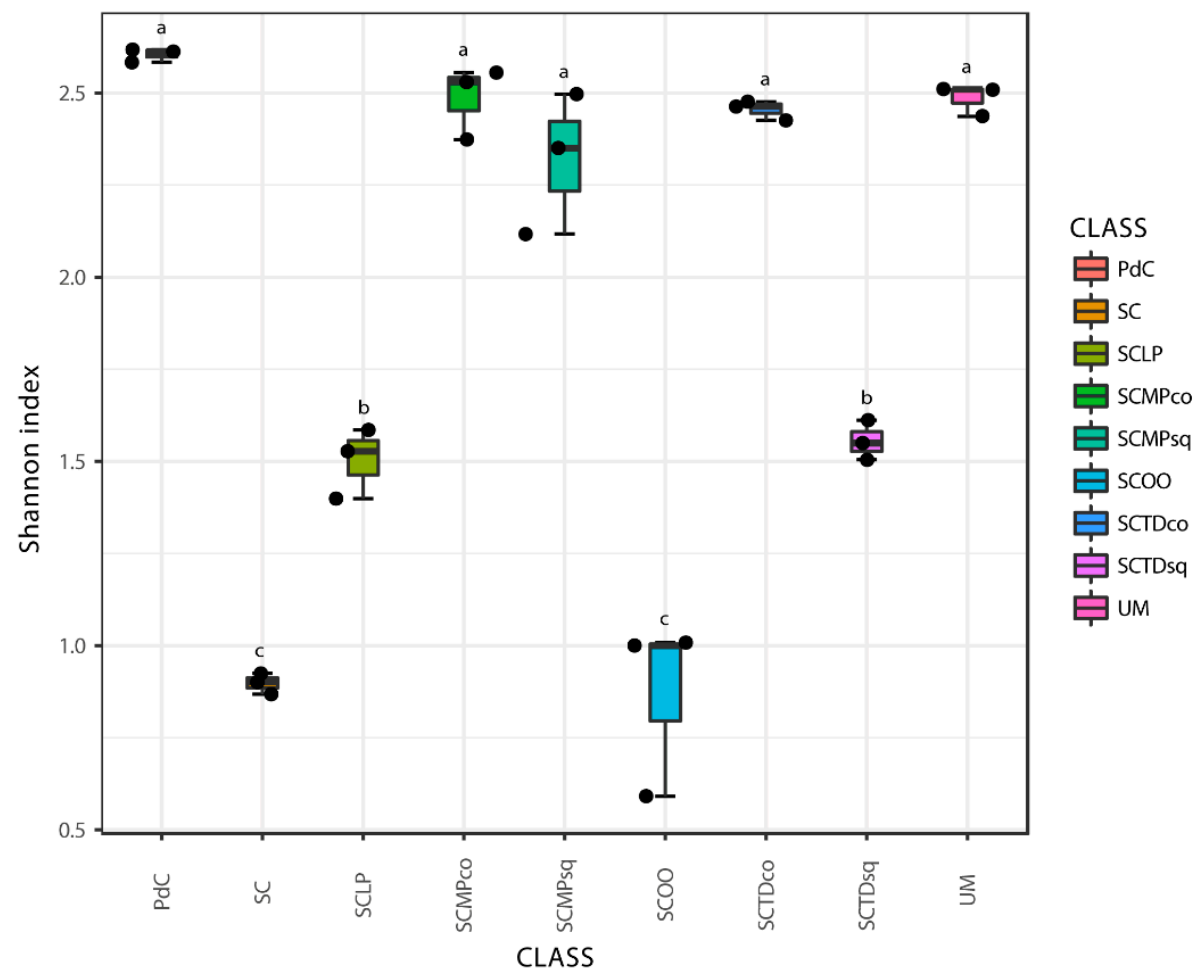

Figure 7. Alpha-diversity estimates based on OTU-data with Shannon indices for the experimental modes tested. Results of ANOVA analysis are shown as letters on the corresponding data.

Even if some trends appeared clear, poor significance in term of richness (Chao1 index), has been depicted (Figure 6). Only the combination of S. cerevisiae + M. pulcherrima sequentially inoculated to induce alcoholic fermentation led to a significantly richer malolactic bacterial consortium. On the opposite, richness and dominance (Shannon index) (Figure 7) were similarly highest for trials PdC, UM, SCMPco, SCTDco, SCMPsq, followed by the experimental modes, SCTDsq and SCLP. Finally, richness and diversity were significantly lower for samples inoculated with $S$. cerevisiae alone, and with S. cerevisiae and O. oeni.

Another downstream output, generated from NGS data, is beta-diversity. Ordination plot in Figure 8, providing different cluster affinities, offers a measure of differences in bacterial community composition for the different malolactic consortia. PCoA demonstrated a clear separation of experimental mode clusters (Figure 8). The significance in the highlighted separation was proved by PERMANOVA tests among samples $(p<0.001)$. In particular, the three samples (PdC, SCTDco, and SCMPco) formed a separated thigh cluster. Two couples of samples, (i) inoculated with S. cerevisiae and with S. cerevisiae + O. oeni, and (ii) inoculated with S. cerevisiae + T. delbrueckii (sq) and S. cerevisiae + L. plantarum, respectively co-clustered. While uninoculated must, and samples inoculated with S. cerevisiae $+M$. pulcherrima (sq), formed separate congregations.

Considering the taxonomic composition of bacterial communities of the malolactic consortia, associated with the tested management of the microbial resources, Firmicutes were the dominant phylum in the experimental modes SC, SCTDsq, SCOO, and SCLP (Figure 9). This dominance was less pronounced in the samples SCMPsq and SCMPco. On the opposite, the increased relative abundance of Proteobacteria led to their dominance in the trials PdC, UM, and SCTDco (Figure 9). It is important to underline that, the presence of Cyanobacteria among the Phyla depicted would be ascribable to the amplification/sequencing of the 16S rRNA gene present in the DNA of Vitis vinifera chloroplasts [49] (a hypothesis strengthened by the evidence that it was not possible to assign with reasonable confidence Cyanobacteria OTUs at a finer than level Phylum). Diversity, at the genus level (Figure 10), was clearly in accordance with the diversity measured with $\alpha$ - and $\beta$-diversity (Figures 6-8), providing information 
that can help explain the observed variability. It is possible to depict a certain correspondence between microbial consortium composition in terms of malolactic bacteria (genera Oenoccoccus, Lactobacillus, Lactococcus) (Figure 10) and the malolactic performances. This relation becomes clear in the case of dominance of Oenococcus genus.

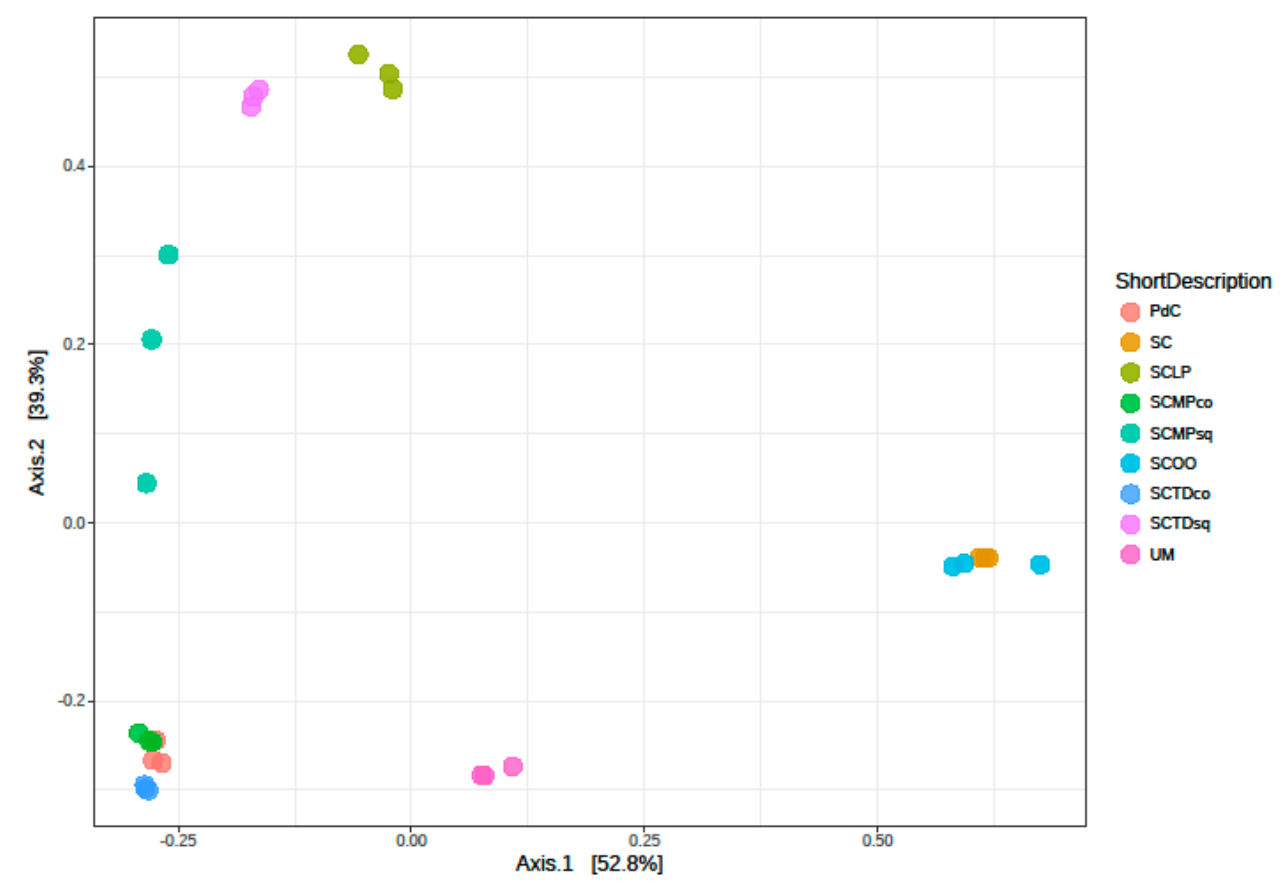

Figure 8. Principal Coordinates Analysis (PCoA) of the samples.

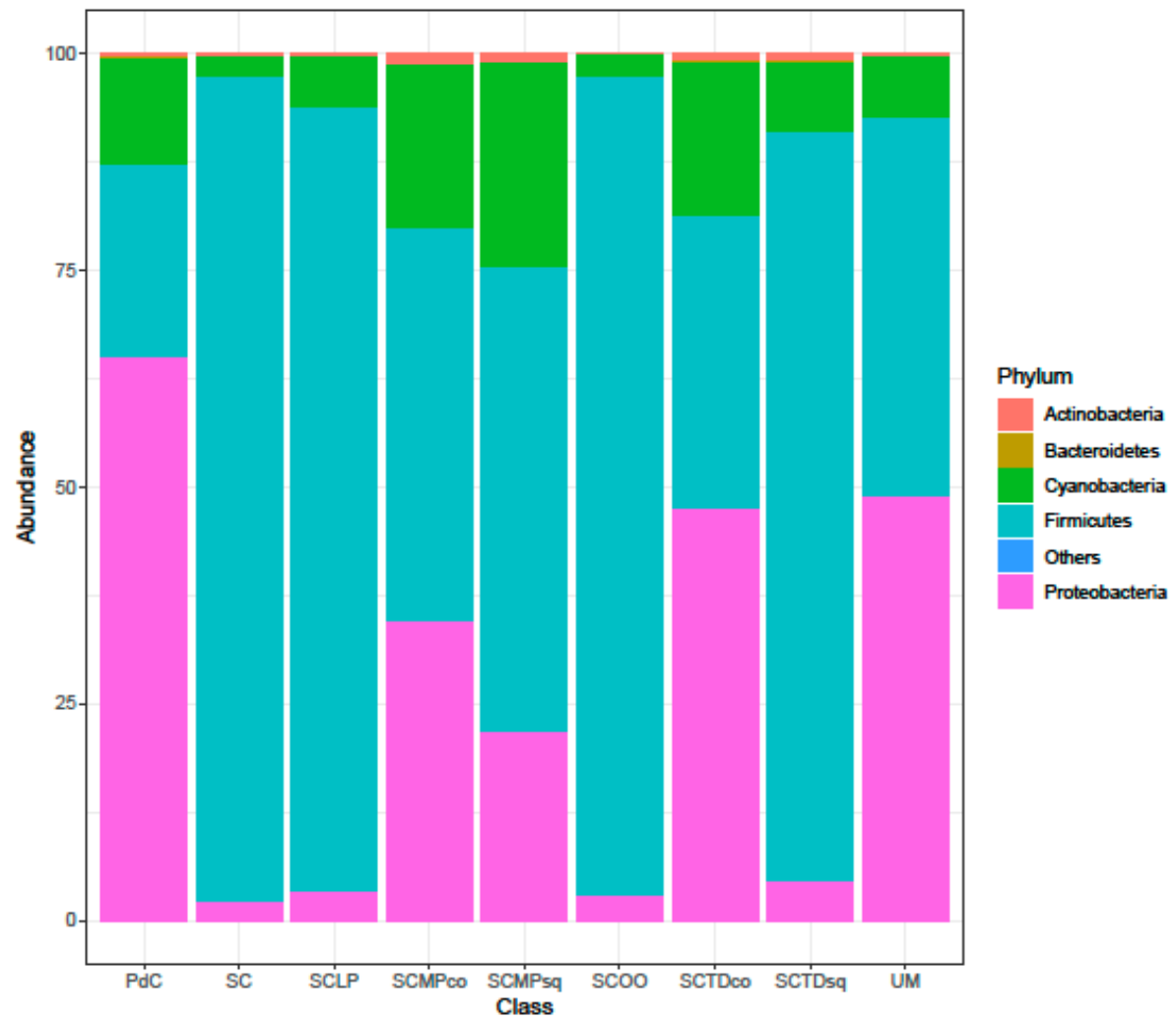

Figure 9. Bacterial community composition at the Phylum level of explored experimental modes. The data represent the means of three replicates. Results of ANOVA analysis are shown as letters on the corresponding data. 




Figure 10. Bacterial community composition at Genus level of explored experimental modes. The data represent the means of three replicates. Results of ANOVA analysis are shown as letters on the corresponding data.

In Figures 11-15, we report the 16S rRNA gene metagenomics data with the abundance of the number of reads for the principal bacterial genera with a pro-technological relevance [i.e., Oenococcus (Figure 11), Lactobacillus (Figure 12), Lactococcus (Figure 13)], and spoilage potential [i.e., Acetobacter (Figure 14), Gluconobacter (Figure 15)] in enology. In general, if we consider the more basic management of microbial resources related to alcoholic fermentation, 'pied-de-cuve' practice, un-inoculated must and inoculation of a selected strain of S. cerevisiae, we found that the genera of pro-technological significance were more abundant in the sample with a controlled alcoholic fermentation, followed by the uninoculated must, and by the 'pied-de-cuve' samples. In contrast, spoilage bacteria were more concentrated in the 'pied-de-cuve' sample, followed by the uninoculated trial. Comparing the experimental modes SC with the inoculation, in combination with a selected non-Saccharomyces strain, we found that inoculation with $T$. delbrueckii/M. pulcherrima, not only radically affects the composition of malolactic consortium, but we also found it to be associated with the prevalence of specific genera of oenological significance. In addition, it was also evident that the time of inoculation had an influence on the non-Saccharomyces commercial yeast. Specifically, within the pro-technological consortia, Oenococcus genus dominated the experimental mode SC and, to a lesser extent, by the 'un-inoculated must'. Lactobacillus was detected as prevailing malolactic genus in the trial SCTDsq and SCMPsq, thus in the cases where the non-Saccharomyces strains were sequentially inoculated, with respect of the $S$. cerevisiae strain. In contrast, in the case of co-inoculation, the most representative LAB genus was Lactococcus, more so for sample SCMPco than in SCTDco. Lactococcus was also find to be significantly present in the sample where alcoholic fermentation was performed through the practice of 'pied-de-cuve'. Considering spoilage bacteria of oenological significance, Acetobacter and Gluconobacter genera were found highly associated with uncontrolled alcoholic fermentations (UM and PdC), and to the experimental mode SCMPco, SCMPsq, and SCTDco (Figures 14 and 15). Finally, we monitored the consortia associated with the inoculation of commercially available LAB, namely Oenococcus oeni and Lactobacillus plantarum, to promote malolactic fermentation. In both cases, we detected a considerable 
preponderance of the corresponding genus (Oenococcus in the sample SCOO and Lactobacillus, in sample SCLP), which suggests that the protechnological strains implanted well. Interestingly, in association with inoculation of the commercial L. plantarum strain, we were able to observe a significant presence of Oenoccocus genus.

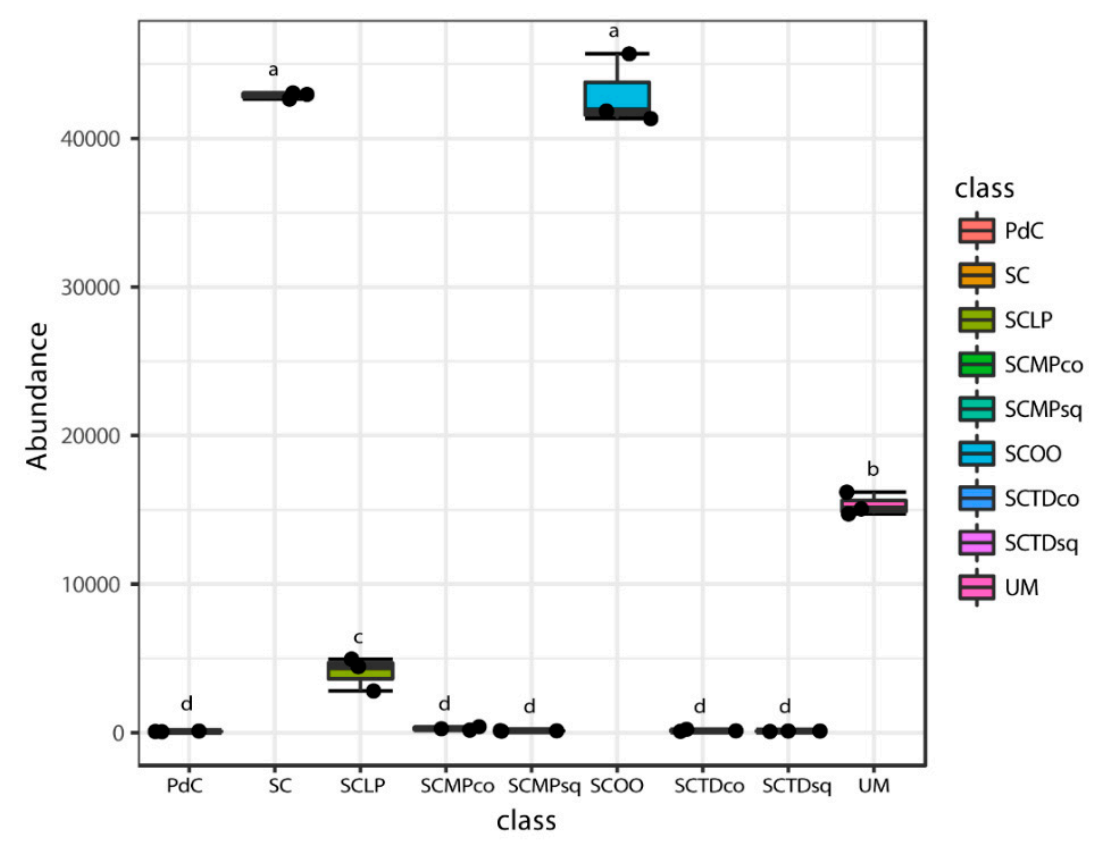

Figure 11. Boxplots showing the abundance of Oenococcus genus across tested experimental conditions. The data shown are an average of three independent experiments. Results of ANOVA analysis are shown as letters on the corresponding data.

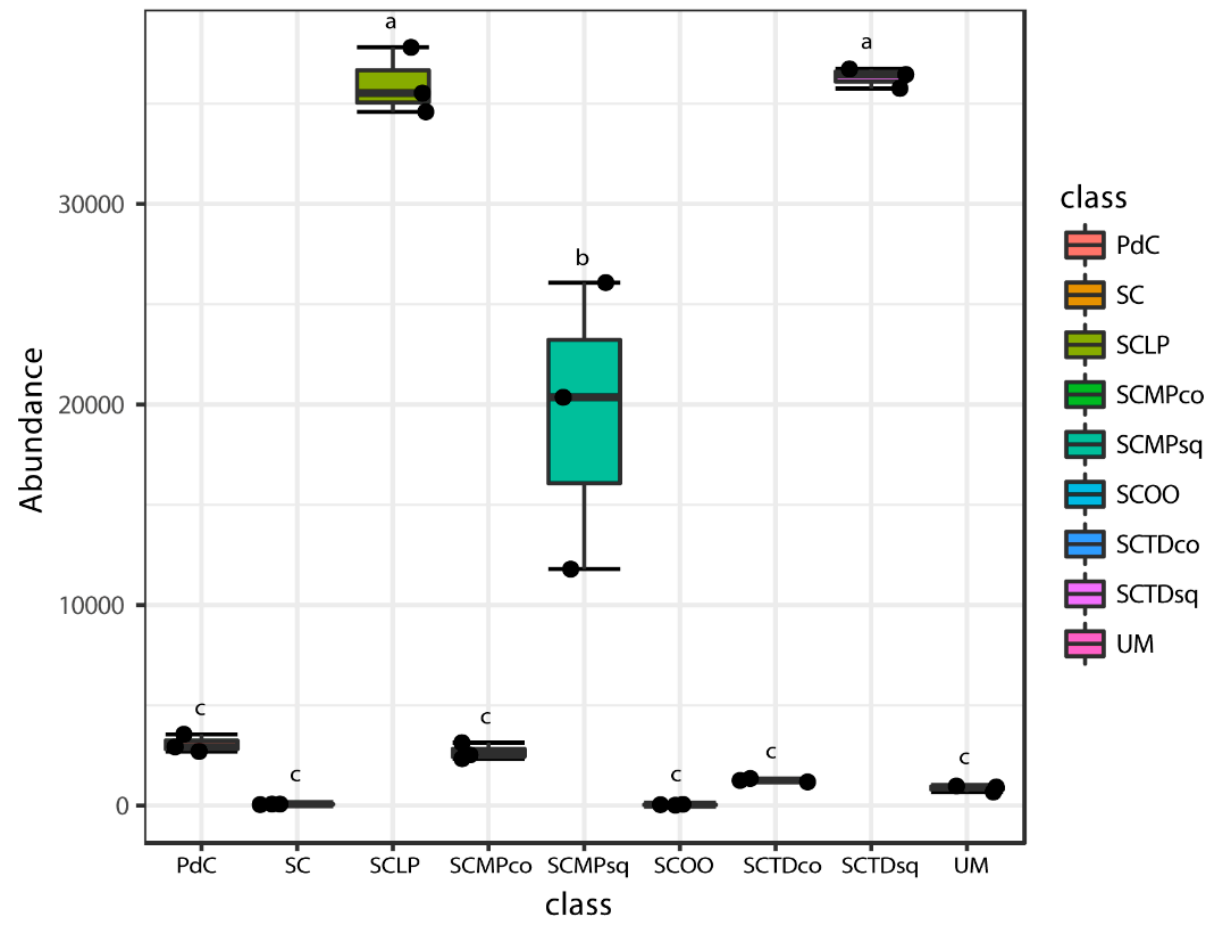

Figure 12. Boxplots showing the abundance of Lactobacillus genus across tested experimental conditions. The data shown are an average of three independent experiments. Results of ANOVA analysis are shown as letters on the corresponding data. 


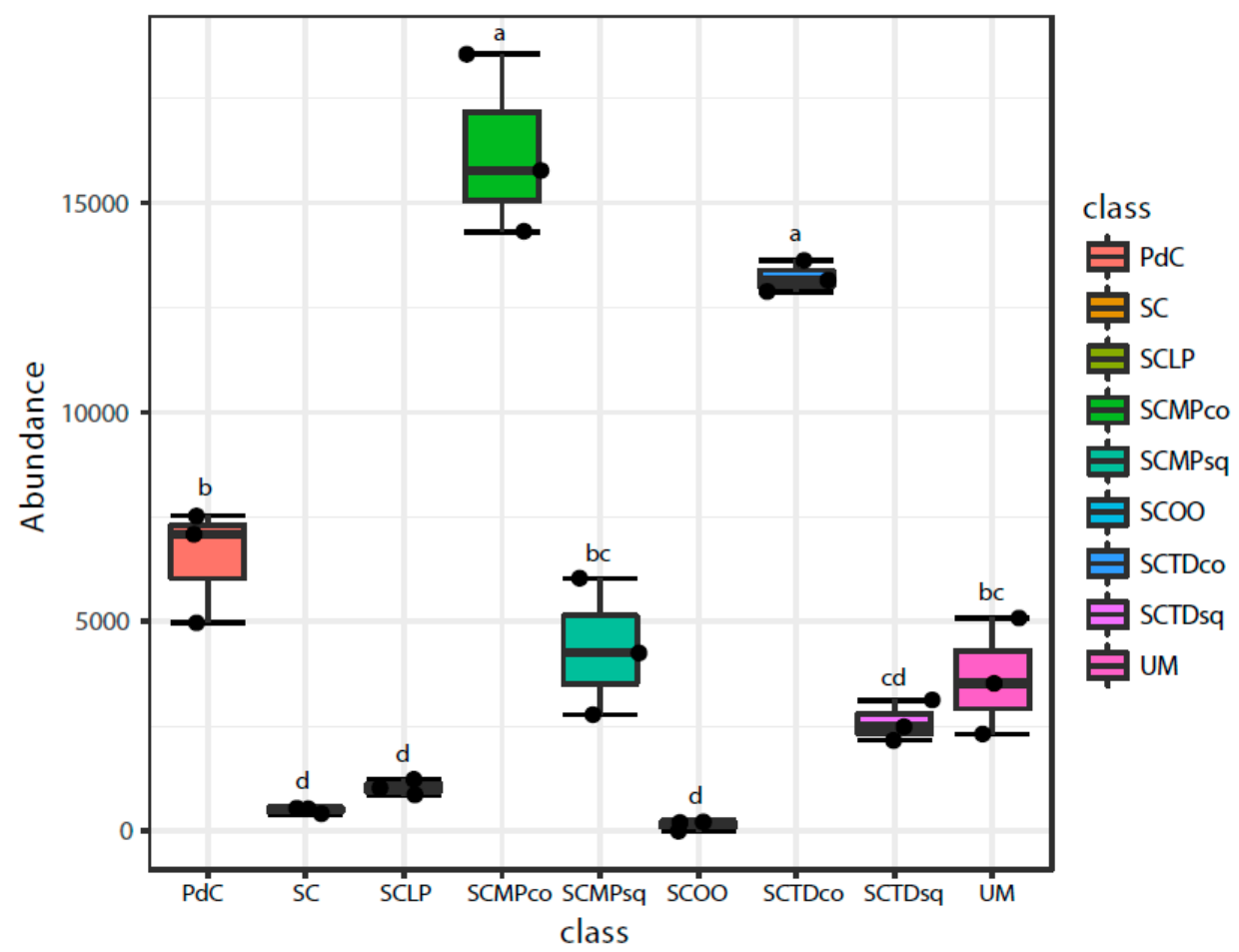

Figure 13. Boxplots showing the abundance of Lactococcus genus across tested experimental conditions. The data shown are an average of three independent experiments. Results of ANOVA analysis are shown as letters on the corresponding data.

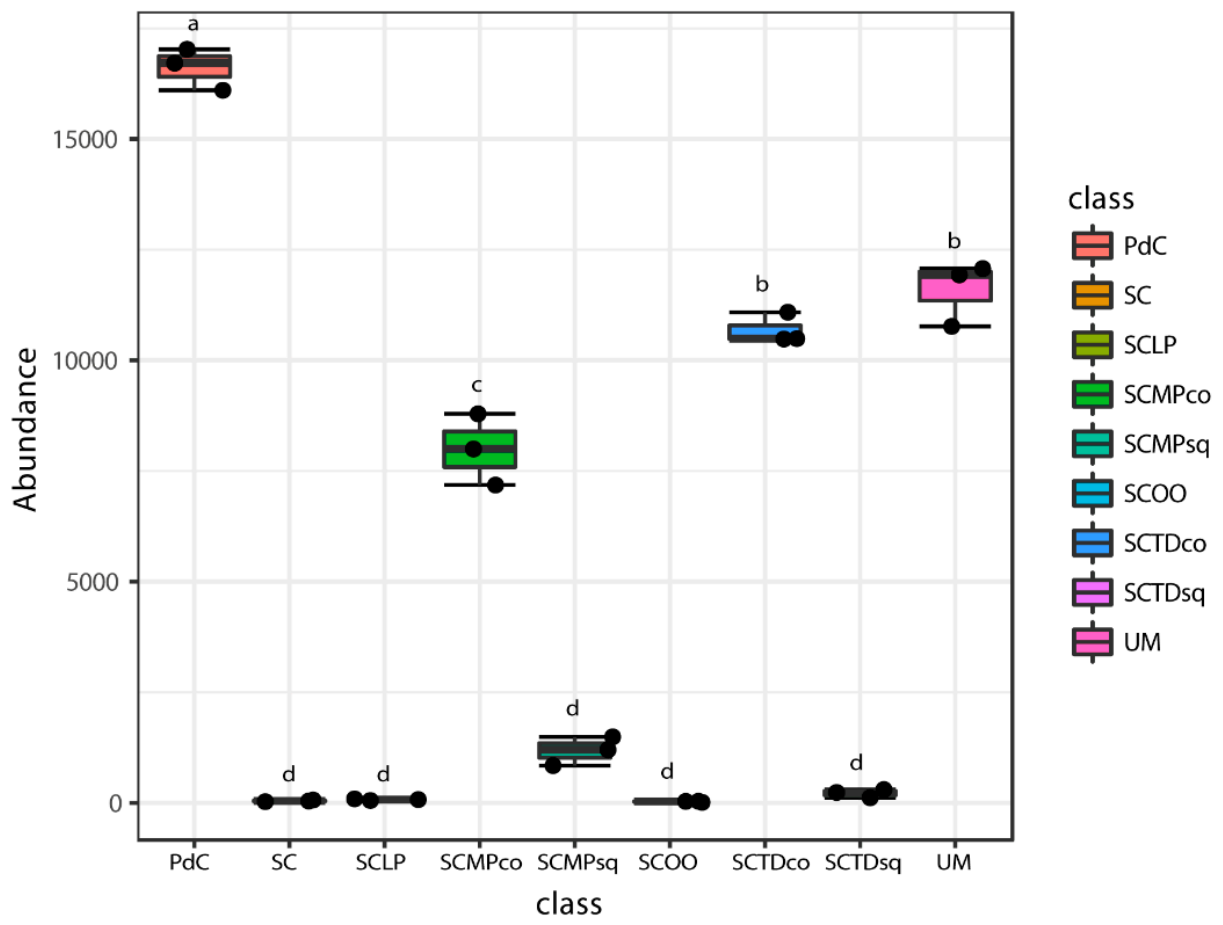

Figure 14. Boxplots showing the abundance of Acetobacter genus across tested experimental conditions. The data shown are an average of three independent experiments. Results of ANOVA analysis are shown as letters on the corresponding data. 


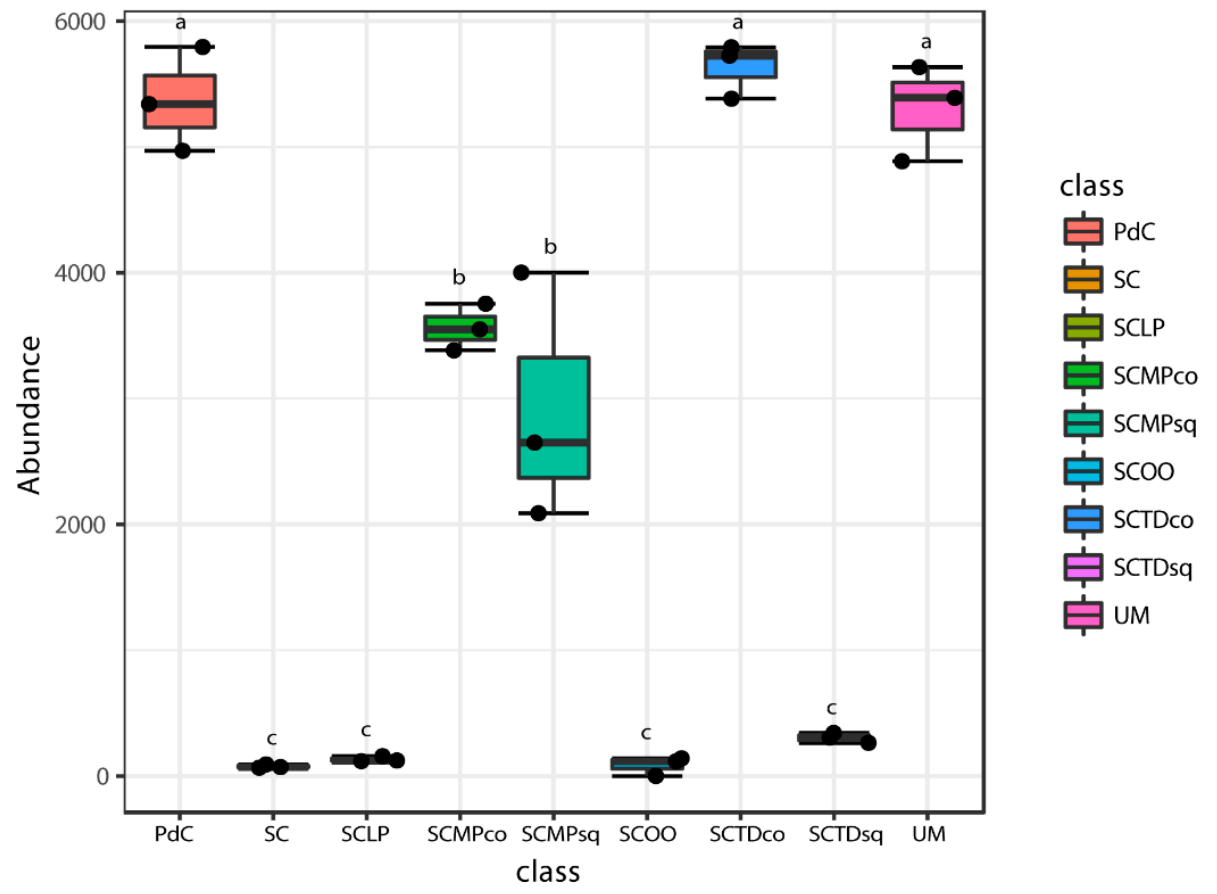

Figure 15. Boxplots showing the abundance of Gluconobacter genus across tested experimental conditions. The data shown are an average of three independent experiments. Results of ANOVA analysis are shown as letters on the corresponding data.

\section{Discussion}

During the vinification process, we can generally recognize three main stages of interest, involving microorganisms: (1) Preliminary step of the AF associated with the dominance of the non-Saccharomyces yeasts, (2) the main phase of AF associated with the growth of Saccharomyces yeasts, and (3) MLF associated with the dominance of LAB. Wine quality strongly depends on the diversity of species and strains, linked to the microbial consortium, which continuously evolves during the process of winemaking [50]. The present work is one of the few studies dealing with the meta-taxonomic characterization of malolactic consortia in wine [33,38,39]. It is also the first study that proposes the application of NGS-based approaches, which explore the the different uses of eukaryotic resources, which have been exploited to drive the AF on the indigenous prokaryotic diversity, connected to malolactic fermentation. In addition, for the first time, we use a meta-taxonomic approach to monitor the effect of the inoculation of malolactic starter cultures after alcoholic fermentation. In particular, among the experimental modes, we tested different uses of microbial resources, commonly applied in wineries, relying (i) on spontaneous yeast consortium (un-inoculated must and 'pied-de-cuve' practices), and (ii) on the inoculation of selected pro-technological strains belonging to species, Saccharomyces cerevisiae [51,52], Torulaspora delbrueckii [20], M. pulcherrima [53], O. oeni [54], and Lactobacillus plantarum [55]. In all the explored experimental modes, malolactic fermentation, and the associated spontaneous consortium, were monitored in order to understand the phenomena (the management of microbial resources), which may be crucial to the quality of final wine [56]. In addition, the investigations of the autochthonous microbiota, linked to wine fermentation, and the relationship within the microbial consortium, are gaining increasing interest, even in light of the relevance of the so-called, 'microbial terroir' [19,34,38,57].

The classical analysis was performed to monitor malolactic fermentation, and it mainly looked at $\mathrm{pH}$, malic acid degradation, lactic acid production, and microbial counts, which were, in general, coherent. Together with the direct proportion among malic acid degradation, lactic acid production, and lactic acid bacteria level, even the slight deacidification of about 0.2 in terms of $\mathrm{pH}$, clearly indicate the occurrence of MLF [57]. Our data indicate no consistent malic acid degradation by the non-Saccharomyces strains used (T. delbrueckii, M. pulcherrima). This was in accordance with recent 
evidence that, studying different non-Saccharomyces strains found only Schizosaccharomyces pombe and the Candida zemplinina responsible for a mentionable degradation of this organic acid [28,58].

Concerning malolactic performances, a first relevant observation deals with the efficiency of spontaneous malolactic fermentation, connected to the inoculation of S. cerevisiae, when compared to un-inoculated and 'pied-de-cuve' samples. Our evidence confirms that, what was found in common wine corresponds with the finding related to botrytized wine by Bokulich et al. [33]: Comparing the bacterial diversity between uninoculated and inoculated trials, it is possible to notice a selective pressure exerted by Saccharomyces, mainly in the reduction of acetic acid bacteria. In addition, we found that this reduction in the genera, Acetobacter and Gluconobacter is associated with an opposite trend in the relative abundance of the genus Oenococcus. In this context, PdC sample showed behavior that appeared intermediate between UM and SC samples, in terms of Acetobacter, Gluconobacter, and Oenococcus relative abundance. The variations in malic consumption, followed the Oenococcus relative abundance, confirmed the relevance of this genus in the wine environment, and its significance in terms of MLF performances [59]. Taken together, our finding suggests that the control AF inoculating S. cerevisiae can favor the dominance of Oenococcus, reducing acetic bacteria, and improving MLF [24]. We also clearly indicated the limitations in terms of MLF efficiency in the case of uninoculated must and of 'pied-de-cuve', underlining the risks linked to vinification processes that rely on spontaneous AF $[60,61]$.

Regarding the impact of non-Saccharomyces yeast on the spontaneous malolactic consortium, we report, for the first time, a potential inhibition/delaying of MLF when T. delbrueckii and M. pulcherrima were inoculated. Although our study does not suggest any further information on the possible biological mechanisms responsible for these findings (e.g., nitrogen source preferences, the release of medium chain fatty acids) [26,62], evidence from the recent literature, underline that a possible solution relies on the use of selected starter cultures for MLF. The use of selected resources to drive MLF in wine allowed the possible evaluation of the compatibility of the selected malolactic bacteria, with specific non-Saccharomyces, as recently reported for O. oeni strains, used in combination with T. delbrueckii, M. pulcherrima and Hanseniaspora uvarum strains [28,63-65]. Intriguingly, we also show an effect of the inoculation time of the non-Saccharomyces strains with respect to $S$. cerevisiae resources, which is a fundamental aspect in the concrete winery practices [66].

Furthermore, the preponderance of the genera Oenococcus and Lactobacillus, in association with inoculated and spontaneous MLF, was confirmed $[67,68]$, as well as a potential role for the genus Lactococcus $[69,70]$.

All reported findings highlight the importance in applying optimal yeast management and the MLF strategy to ensure correct completion of MLF and, consequently, to improve wine quality. Furthermore, these preliminary findings suggest that massive sequencing could be a new useful tool for the control malolactic fermentation, not only for the monitoring of AF in wine [71]. The findings highlight the importance of selecting the appropriate sampling point for the NGS analysis, in order to elucidate the composition of the microbial consortia, associated with malic acid degradation. In this light, the monitoring of more time points represents a crucial issue among the future perspectives of this study.

Considering fermented matrices as experimentally tractable microbial ecosystems [72], our study corroborate the potential interest in wine as a model matrix. In fact, there are two temporarily separated fermentative processes (AF and MLF), with the opportunity to study the effects of a perturbation of the first microbial ecosystem (this associated with the alcoholic fermentation) on the second one (this associated with the malolactic fermentation). 


\section{Materials and Methods}

\subsection{Microorganisms}

The following microorganisms were used for must inoculation: The commercially available S. cerevisiae DV10 (Lallemand Inc., Montréal, QC, Canada) [73], the commercially available non-Saccharomyces strains Metschnikowia pulcherrima, and Torulaspora delbrueckii. As lactic acid bacteria (LAB), Oenococcus oeni and Lactobacillus plantarum were used in the fermentation. Starter cultures have been purchased in active dried form. Rehydration procedures were carried out according to suppliers' instructions, and single isolates were selected on agarized YPD medium ( $2 \%$ glucose, $2 \%$ Bacto peptone, $1 \%$ yeast extract) and in MRS (Sharlab, Barcelona, Spain) at $28{ }^{\circ} \mathrm{C}$ (incubated for 2 days; 5 days for $\mathrm{O}$. oeni) for yeasts, and bacteria, respectively. The biomasses used as starter cultures were prepared by growing up to the stationary state the yeasts strains separately in liquid YPD medium and LAB in MRS (Sharlab, Barcelona, Spain) at $28^{\circ} \mathrm{C}$.

\subsection{Vinifications}

Starter cultures were prepared by growing strains in YPD or MRS medium, as described above, and then inoculating the strains into $400 \mathrm{~mL}$ of grape must from the Apulian autochthonous grape varieties 'Uva di Troia' (21ํ Babo; $7.2 \mathrm{~g} / \mathrm{L}$ total acidity; $2.57 \mathrm{~g} / \mathrm{L}$ malic acid; $\mathrm{pH} 3.78$ ). Each fermentation experiment was carried out by performing three simultaneous independent repetitions into sterile 11 bottles, with an air lock and fermented at $20^{\circ} \mathrm{C}$. Using the 3 yeasts (in a different inoculation mode) and $2 \mathrm{LAB}$, a total of 9 different starter culture combinations were carried out (Table 2). In mixed yeast starter cultures, $S$. cerevisiae was inoculated simultaneously with the non-Saccharomyces yeast in a 1:100 proportion $\left(10^{4} \mathrm{CFU} / \mathrm{mL}: 10^{6} \mathrm{CFU} / \mathrm{mL}\right)$ or sequentially at the same cell concentration $24 \mathrm{~h}$ later. Lactic acid bacteria were inoculated $\left(10^{6} \mathrm{CFU} / \mathrm{mL}\right.$ O. oeni; $10^{7} \mathrm{CFU} / \mathrm{mL}$ L. plantarum $)$ after 12 days of yeasts inoculation, when AF was finishing. One uninoculated grape must sample and an inoculated grape must sample, by a "pied de cuve", were used as controls. The kinetics of the fermentation was monitored for 40 days. During this time, L-malic acid, lactic acid and $\mathrm{pH}$ variation were determined by enzymatic kits (Biogamma, Rome, Italy), and with a $\mathrm{pH}$ meter, respectively.

\subsection{Determination of Microbial Population}

The viable count of yeasts during the AF was enumerated on YPD agar medium (Sigma-Aldrich, Saint Louis, MO, USA). Plates were incubated at $28^{\circ} \mathrm{C}$ for $48 \mathrm{~h}$. The viable count of LAB was done in MRS (Sharlab) supplemented with $10 \mathrm{mg} / \mathrm{L}$ cycloheximide (Sigma-Aldrich, Saint Louis, MO, USA) and incubated for $4-7$ days at $28^{\circ} \mathrm{C}$.

\subsection{Genomic DNA Extraction}

Samples of $5 \mathrm{~mL}$ from the wine fermentations, incubated during 30 days, were centrifuged (10000 $\mathrm{rpm}, 5 \mathrm{~min})$, washed with ultrapure water ( $1 \mathrm{vol})$, then with $1 \mathrm{vol}$ of $10 \%$ TEN buffer $(0.1 \mathrm{M}$ Tris- $\mathrm{HCl}$ pH 7.5, 0.05 M EDTA, 0.8 M NaCl) supplemented with polyvidone 10 (PVP) (2\% w/v) (Sigma-Aldrich, Saint Louis, MO, USA), and then twice with ultrapure water ( $1 \mathrm{vol})$. The genomic DNA from the $5 \mathrm{~mL}$ sample, after the washing steps, was extracted with the commercial extraction kit, known as PowerSoil Microbial DNA Isolation Kit (Mo Bio, Carlsbad, CA, USA), according to the manufacturer's instructions.

\subsection{High Throughput Sequencing}

Illumina libraries were prepared using a NEXTflex 16S V4 Amplicon-Seq Kit (Bioo Scientific, Austin, TX, USA). Briefly, from $50 \mathrm{ng}$ of DNA template for each sample, the bacterial V4 region of the 16S rRNA gene was amplified using the universal primers V3F (GTGCCAGCMGCCGCGGTAA) and V4R (GGACTACHVGGGTWTCTAAT) tailed with Illumina barcoded adapters under the following touchdown PCR conditions: A $20 \mu \mathrm{L}$ mixture was prepared for each reaction and included a $1 \times$ reaction 
buffer (TAKARA), $2 \mathrm{mM} \mathrm{Mg}{ }^{2+}, 0.2 \mathrm{mM}$ dNTP, $0.1 \mu \mathrm{M}$ of each primer, $1 \mathrm{U}$ HotStarTaq polymerase (TAKARA) and $2 \mu \mathrm{L}$ template DNA. The cycling programme was: $95^{\circ} \mathrm{C}$ for $2 \mathrm{~min} ; 35$ cycles of $94^{\circ} \mathrm{C}$ for $20 \mathrm{~s}, 55{ }^{\circ} \mathrm{C}$ for $40 \mathrm{~s}, 72{ }^{\circ} \mathrm{C}$ for $1 \mathrm{~min}, 72{ }^{\circ} \mathrm{C}$ for $2 \mathrm{~min}$. PCR products were purified using Agencourt XP AmpureBeads (Beckman Coulter, Brea, CA, USA). The quality of the final products was assessed using a Agilent Bioanalyzer 2100 (Agilent Technologies, Palo Alto, CA, USA). After their quantification with Qubit (Invitrogen, Carlsband, CA, USA), the samples were pooled in equal proportions and sequenced paired-end in an Illumina MiSeq platform (San Diego, CA, USA) with 312 cycles (150 cycles for each paired read and 12 cycles for the barcode sequence) at IGA Technology Services (Udine, Italy). A tailored pipeline has been adopted in order to process raw sequencing data from 16S rRNA gene amplicon sequence analysis. We used the software PEAR [74] to merge paired-end reads from each library. We avoided including sequences with a quality score threshold, lower than 30 and shorter than $200 \mathrm{bp}$, and we processed the assembled reads with QIIME v.1.8 software [75], inspecting for chimeras with the Chimera VSEARCH package [76]. Subsequently, we taxonomically annotated the SILVA reference database [77]. Operational Units (OTUs) were generated with $97 \%$ similarity cutoff using demultiplexed sequences, removing singletons. The operational taxonomic units (OTUs) table was generated using at $97 \%$ similarity. To normalize the variation in-read depth across samples, data were rarefied to the minimum read depth of 45,747 sequences per sample.

\subsection{Statistical Analysis and Estimation of Fungal Alpha and Beta Diversity}

Statistical analysis has been performed using R software [78]. Alpha and Beta diversity analyses were performed using the phyloseq and vegan packages [79,80]. Differences in Chao1, Richness, and Shannon values among the samples were tested using ANOVA and Pairwise Tukey test. Principle Coordinate Analysis (PCoA), based on Bray-Curtis, was used to displaying beta-diversity. The statistical significance of the clustering pattern visualized via PCoA was tested using Permutational ANOVA (PERMANOVA). Differences among the most important Genera ( $>1 \%)$ was investigated via ANOVA and Pairwise Tukey test.

Supplementary Materials: Supplementary materials can be found at http://www.mdpi.com/1422-0067/20/16/ 3980/s1.

Author Contributions: Conceptualization, C.B., M.F., P.R., G.S., and V.C.; methodology, C.B., L.B. (Luigimaria Borruso), and V.C; investigation, C.B., M.F., M.T., and P.R.; resources, G.S. and L.B. (Lorenzo Brusetti); data curation, C.B., L.B. (Luigimaria Borruso), and V.C; writing-original draft preparation, C.B. and V.C; writing-review and editing, C.B., L.B. (Luigimaria Borruso), M.F., M.T., P.R, L.B. (Lorenzo Brusetti), and G.S.; supervision, G.S. and L.B. (Lorenzo Brusetti); project administration, V.C.; funding acquisition, V.C.

Funding: This research was funded by 'Fondazione Puglia' [http://www.fondazionepuglia.it/] under the Program 'Ricerca Scientifica e Tecnologica - Bando Ricercatori 2015' (Project title: “A metagenomic-based approach for the characterization of bacterial diversity associated with spontaneous malolactic fermentations in wine").

Acknowledgments: We wish to acknowledge 'Fondazione Puglia' for financial support of the project. We also thank the Editor and the three anonymous reviewers whose comments have greatly improved this manuscript.

Conflicts of Interest: The authors declare no conflict of interest.

\section{Abbreviations}

$\begin{array}{ll}\text { AF } & \text { Alcoholic Fermentation } \\ \text { MLF } & \text { Malolactic Fermentation } \\ \text { LAB } & \text { Lactic Acid Bacteria } \\ \text { OTUs } & \text { Operational Units } \\ \text { NGS } & \text { Next Generation Sequencing }\end{array}$




\section{References}

1. Liu, Y.; Rousseaux, S.; Tourdot-Maréchal, R.; Sadoudi, M.; Gougeon, R.; Schmitt-Kopplin, P.; Alexandre, H. Wine microbiome: A dynamic world of microbial interactions. Crit. Rev. Food Sci. Nutr. 2017, 57, 856-873. [CrossRef] [PubMed]

2. Ciani, M.; Capece, A.; Comitini, F.; Canonico, L.; Siesto, G.; Romano, P. Yeast Interactions in Inoculated Wine Fermentation. Front. Microbiol. 2016, 7, 555. [CrossRef] [PubMed]

3. Belda, I.; Ruiz, J.; Esteban-Fernández, A.; Navascués, E.; Marquina, D.; Santos, A.; Moreno-Arribas, M.V. Microbial Contribution to Wine Aroma and Its Intended Use for Wine Quality Improvement. Molecules 2017, 22, 189. [CrossRef] [PubMed]

4. Bauer, R.; Dicks, L.M.T. Control of Malolactic Fermentation in Wine. A Review. South Afr. J. Enol. Vitic. 2017, 25, 74-88. [CrossRef]

5. Campbell-Sills, H.; Capozzi, V.; Romano, A.; Cappellin, L.; Spano, G.; Breniaux, M.; Lucas, P.; Biasioli, F. Advances in wine analysis by PTR-ToF-MS: Optimization of the method and discrimination of wines from different geographical origins and fermented with different malolactic starters. Int. J. Mass Spectrom. 2016, 397-398, 42-51. [CrossRef]

6. Berbegal, C.; Spano, G.; Tristezza, M.; Grieco, F.; Capozzi, V. Microbial Resources and Innovation in the Wine Production Sector. S. Afr. J. Enol. Vitic. 2017, 38, 156-166. [CrossRef]

7. Garofalo, C.; Arena, M.P.; Laddomada, B.; Cappello, M.S.; Bleve, G.; Grieco, F.; Beneduce, L.; Berbegal, C.; Spano, G.; Capozzi, V. Starter Cultures for Sparkling Wine. Fermentation 2016, 2, 21. [CrossRef]

8. Petruzzi, L.; Capozzi, V.; Berbegal, C.; Corbo, M.R.; Bevilacqua, A.; Spano, G.; Sinigaglia, M. Microbial Resources and Enological Significance: Opportunities and Benefits. Front. Microbiol. 2017, 8, 995. [CrossRef] [PubMed]

9. Tempère, S.; Marchal, A.; Barbe, J.-C.; Bely, M.; Masneuf-Pomarede, I.; Marullo, P.; Albertin, W. The complexity of wine: Clarifying the role of microorganisms. Appl. Microbiol. Biotechnol. 2018, 102, 3995-4007. [CrossRef]

10. Russo, P.; Capozzi, V.; Spano, G.; Corbo, M.R.; Sinigaglia, M.; Bevilacqua, A. Metabolites of Microbial Origin with an Impact on Health: Ochratoxin A and Biogenic Amines. Front. Microbiol. 2016, 7, 482. [CrossRef]

11. Escribano, R.; González-Arenzana, L.; Portu, J.; Garijo, P.; López-Alfaro, I.; López, R.; Santamaría, P.; Gutiérrez, A.R. Wine aromatic compound production and fermentative behaviour within different non-Saccharomyces species and clones. J. Appl. Microbiol. 2008, 124, 1521-1531. [CrossRef] [PubMed]

12. Tofalo, R.; Patrignani, F.; Lanciotti, R.; Perpetuini, G.; Schirone, M.; Di Gianvito, P.; Pizzoni, D.; Arfelli, G.; Suzzi, G. Aroma Profile of Montepulciano d'Abruzzo Wine Fermented by Single and Co-culture Starters of Autochthonous Saccharomyces and Non-saccharomyces Yeasts. Front. Microbiol. 2016, 7, 610. [CrossRef] [PubMed]

13. Chasseriaud, L.; Coulon, J.; Marullo, P.; Albertin, W.; Bely, M. New oenological practice to promote non-Saccharomyces species of interest: Saturating grape juice with carbon dioxide. Appl. Microbiol. Biotechnol. 2018, 102, 3779-3791. [CrossRef] [PubMed]

14. Canonico, L.; Comitini, F.; Oro, L.; Ciani, M. Sequential Fermentation with Selected Immobilized Non-Saccharomyces Yeast for Reduction of Ethanol Content in Wine. Front. Microbiol. 2016, 7, 278. [CrossRef] [PubMed]

15. Escribano, R.; González-Arenzana, L.; Garijo, P.; Berlanas, C.; López-Alfaro, I.; López, R.; Gutiérrez, A.R.; Santamaría, P. Screening of enzymatic activities within different enological non-Saccharomyces yeasts. J. Food Sci. Technol. 2017, 54, 1555-1564. [CrossRef]

16. Roudil, L.; Russo, P.; Berbegal, C.; Albertin, W.; Spano, G.; Capozzi, V. Non-Saccharomyces Commercial Starter Cultures: Scientific Trends, Recent Patents and Innovation in the Wine Sector. Recent Pat. Food Nutr. Agric. 2019. [CrossRef] [PubMed]

17. Garofalo, C.; Russo, P.; Beneduce, L.; Massa, S.; Spano, G.; Capozzi, V. Non-Saccharomyces biodiversity in wine and the 'microbial terroir': A survey on Nero di Troia wine from the Apulian region, Italy. Ann. Microbiol. 2016, 66, 143-150. [CrossRef]

18. Comitini, F.; Capece, A.; Ciani, M.; Romano, P. New insights on the use of wine yeasts. Curr. Opin. Food Sci. 2017, 13, 44-49. [CrossRef]

19. Knight, S.; Klaere, S.; Fedrizzi, B.; Goddard, M.R. Regional microbial signatures positively correlate with differential wine phenotypes: Evidence for a microbial aspect to terroir. Sci. Rep. 2015, 5, 14233. [CrossRef] 
20. Bely, M.; Stoeckle, P.; Masneuf-Pomarède, I.; Dubourdieu, D. Impact of mixed Torulaspora delbrueckii-Saccharomyces cerevisiae culture on high-sugar fermentation. Int. J. Food Microbiol. 2008, 122, 312-320. [CrossRef]

21. Comitini, F.; Gobbi, M.; Domizio, P.; Romani, C.; Lencioni, L.; Mannazzu, I.; Ciani, M. Selected non-Saccharomyces wine yeasts in controlled multistarter fermentations with Saccharomyces cerevisiae. Food Microbiol. 2011, 28, 873-882. [CrossRef] [PubMed]

22. Wang, C.; Mas, A.; Esteve-Zarzoso, B. The Interaction between Saccharomyces cerevisiae and Non-Saccharomyces Yeast during Alcoholic Fermentation Is Species and Strain Specific. Front. Microbiol. 2016, 7, 502. [CrossRef] [PubMed]

23. Ciani, M.; Comitini, F. Yeast interactions in multi-starter wine fermentation. Curr. Opin. Food Sci. 2015, 1, 1-6. [CrossRef]

24. Alexandre, H.; Costello, P.J.; Remize, F.; Guzzo, J.; Guilloux-Benatier, M. Saccharomyces cerevisiaeOenococcus oeni interactions in wine: Current knowledge and perspectives. Int. J. Food Microbiol. 2004, 93, 141-154. [CrossRef] [PubMed]

25. Nehme, N.; Mathieu, F.; Taillandier, P. Quantitative study of interactions between Saccharomyces cerevisiae and Oenococcus oeni strains. J. Ind. Microbiol. Biotechnol. 2008, 35, 685-693. [CrossRef] [PubMed]

26. Balmaseda, A.; Bordons, A.; Reguant, C.; Bautista-Gallego, J. Non-Saccharomyces in Wine: Effect Upon Oenococcus oeni and Malolactic Fermentation. Front. Microbiol. 2018, 9, 534. [CrossRef] [PubMed]

27. Du Plessis, H.; du Toit, M.; Nieuwoudt, H.; van der Rijst, M.; Kidd, M.; Jolly, N. Effect of Saccharomyces, Non-Saccharomyces Yeasts and Malolactic Fermentation Strategies on Fermentation Kinetics and Flavor of Shiraz Wines. Fermentation 2017, 3, 64. [CrossRef]

28. Du Plessis, H.W.; du Toit, M.; Hoff, J.W.; Hart, R.S.; Ndimba, B.K.; Jolly, N.P. Characterisation of Non-Saccharomyces yeasts using different methodologies and evaluation of their compatibility with malolactic fermentation. S. Afr. J. Enol. Vitic. 2017, 38, 46-63. [CrossRef]

29. Sumby, K.M.; Bartle, L.; Grbin, P.R.; Jiranek, V. Measures to improve wine malolactic fermentation. Appl. Microbiol. Biotechnol. 2019, 103, 2033-2051. [CrossRef]

30. Mayo, B.; Rachid, C.T.; Alegría, Á.; Leite, A.M.; Peixoto, R.S.; Delgado, S. Impact of Next Generation Sequencing Techniques in Food Microbiology. Curr. Genomics. 2014, 15, 293-309. [CrossRef]

31. Morgan, H.H.; du Toit, M.; Setati, M.E. The Grapevine and Wine Microbiome: Insights from High-Throughput Amplicon Sequencing. Front. Microbiol. 2017, 8, 820. [CrossRef] [PubMed]

32. Leveau, J.H.J.; Tech, J.J. Grapevine microbiomics: Bacterial diversity on grape leaves and berries revealed by high-throughput sequence analysis of 16s rRNA amplicons. Acta Hortic. 2011, 905, 31-42. [CrossRef]

33. Bokulich, N.A.; Joseph, C.M.L.; Allen, G.; Benson, A.K.; Mills, D.A. Next-Generation Sequencing Reveals Significant Bacterial Diversity of Botrytized Wine. PLoS ONE 2012, 7, e36357. [CrossRef] [PubMed]

34. Bokulich, N.A.; Thorngate, J.H.; Richardson, P.M.; Mills, D.A. Microbial biogeography of wine grapes is conditioned by cultivar, vintage, and climate. Proc. Natl. Acad. Sci. USA 2014, 111, E139-E148. [CrossRef] [PubMed]

35. Pinto, C.; Pinho, D.; Cardoso, R.; Custódio, V.; Fernandes, J.; Sousa, S.; Pinheiro, M.; Egas, C.; Gomes, A.C. Wine fermentation microbiome: A landscape from different Portuguese wine appellations. Front. Microbiol. 2015, 6, 905. [CrossRef] [PubMed]

36. Bokulich, N.A.; Swadener, M.; Sakamoto, K.; Mills, D.A.; Bisson, L.F. Sulfur Dioxide Treatment Alters Wine Microbial Diversity and Fermentation Progression in a Dose-Dependent Fashion. Am. J. Enol. Vitic. 2015, 66, 73-79. [CrossRef]

37. Piao, H.; Hawley, E.; Kopf, S.; DeScenzo, R.; Sealock, S.; Henick-Kling, T.; Hess, M. Insights into the bacterial community and its temporal succession during the fermentation of wine grapes. Front. Microbiol. 2015, 6, 809. [CrossRef]

38. Bokulich, N.A.; Collins, T.S.; Masarweh, C.; Allen, G.; Heymann, H.; Ebeler, S.E.; Mills, D.A. Associations among Wine Grape Microbiome, Metabolome, and Fermentation Behavior Suggest Microbial Contribution to Regional Wine Characteristics. MBio 2016, 7, e00631-16. [CrossRef]

39. Marzano, M.; Fosso, B.; Manzari, C.; Grieco, F.; Intranuovo, M.; Cozzi, G.; Mulè, G.; Scioscia, G.; Valiente, G.; Tullo, A.; et al. Complexity and Dynamics of the Winemaking Bacterial Communities in Berries, Musts, and Wines from Apulian Grape Cultivars through Time and Space. PLoS ONE 2016, 11, e0157383. [CrossRef] 
40. Salvetti, E.; Campanaro, S.; Campedelli, I.; Fracchetti, F.; Gobbi, A.; Tornielli, G.B.; Torriani, S.; Felis, G.E. Whole-Metagenome-Sequencing-Based Community Profiles of Vitis vinifera L. cv. Corvina Berries Withered in Two Post-harvest Conditions. Front. Microbiol. 2016, 7, 937.

41. Mezzasalma, V.; Sandionigi, A.; Guzzetti, L.; Galimberti, A.; Grando, M.S.; Tardaguila, J.; Labra, M. Geographical and Cultivar Features Differentiate Grape Microbiota in Northern Italy and Spain Vineyards. Front. Microbiol. 2018, 9, 946. [CrossRef] [PubMed]

42. Lleixà, J.; Kioroglou, D.; Mas, A.; del Carmen Portillo, M. Microbiome dynamics during spontaneous fermentations of sound grapes in comparison with sour rot and Botrytis infected grapes. Int. J. Food Microbiol. 2018, 281, 36-46.

43. Vitulo, N.; Lemos, W.J.F.; Calgaro, M.; Confalone, M.; Felis, G.E.; Zapparoli, G.; Nardi, T. Bark and Grape Microbiome of Vitis vinifera: Influence of Geographic Patterns and Agronomic Management on Bacterial Diversity. Front. Microbiol. 2018, 9, 3203. [CrossRef] [PubMed]

44. Gao, F.; Chen, J.; Xiao, J.; Cheng, W.; Zheng, X.; Wang, B.; Shi, X. Microbial community composition on grape surface controlled by geographical factors of different wine regions in Xinjiang, China. Food Res. Int. 2019, 122, 348-360. [CrossRef] [PubMed]

45. Sirén, K.; Mak, S.S.T.; Melkonian, C.; Carøe, C.; Swiegers, J.H.; Molenaar, D.; Fischer, U.; Gilbert, M.T.P. Taxonomic and Functional Characterization of the Microbial Community During Spontaneous in vitro Fermentation of Riesling Must. Front. Microbiol. 2019, 10, 697. [CrossRef]

46. Clavijo, A.; Calderón, I.L.; Paneque, P. Yeast assessment during alcoholic fermentation inoculated with a natural "pied de cuve" or a commercial yeast strain. World J. Microbiol. Biotechnol. 2011, 27, 1569-1577. [CrossRef]

47. Mira de Orduña, R. Climate change associated effects on grape and wine quality and production. Food Res. Int. 2010, 43, 1844-1855. [CrossRef]

48. Capozzi, V.; Russo, P.; Beneduce, L.; Weidmann, S.; Grieco, F.; Guzzo, J.; Spano, G. Technological properties of Oenococcus oeni strains isolated from typical southern Italian wines. Lett. Appl. Microbiol. 2010, 50, 327-334. [CrossRef]

49. Stefanini, I.; Cavalieri, D. Metagenomic Approaches to Investigate the Contribution of the Vineyard Environment to the Quality of Wine Fermentation: Potentials and Difficulties. Front. Microbiol. 2018. [CrossRef]

50. Barata, A.; Malfeito-Ferreira, M.; Loureiro, V. The microbial ecology of wine grape berries. Int. J. Food Microbiol. 2012, 153, 243-259. [CrossRef]

51. Tofalo, R.; Perpetuini, G.; Schirone, M.; Fasoli, G.; Aguzzi, I.; Corsetti, A.; Suzzi, G. Biogeographical characterization of Saccharomyces cerevisiae wine yeast by molecular methods. Front. Microbiol. 2013, 4, 166. [CrossRef] [PubMed]

52. Capece, A.; Granchi, L.; Guerrini, S.; Mangani, S.; Romaniello, R.; Vincenzini, M.; Romano, P. Diversity of Saccharomyces cerevisiae Strains Isolated from Two Italian Wine-Producing Regions. Front. Microbiol. 2016, 7, 1018. [CrossRef] [PubMed]

53. Contreras, A.; Curtin, C.; Varela, C. Yeast population dynamics reveal a potential "collaboration" between Metschnikowia pulcherrima and Saccharomyces uvarum for the production of reduced alcohol wines during Shiraz fermentation. Appl. Microbiol. Biotechnol. 2015, 99, 1885-1895. [CrossRef] [PubMed]

54. Garofalo, C.; El Khoury, M.; Lucas, P.; Bely, M.; Russo, P.; Spano, G.; Capozzi, V. Autochthonous starter cultures and indigenous grape variety for regional wine production. J. Appl. Microbiol. 2015, 118, 1395-1408. [CrossRef] [PubMed]

55. Berbegal, C.; Peña, N.; Russo, P.; Grieco, F.; Pardo, I.; Ferrer, S.; Spano, G.; Capozzi, V. Technological properties of Lactobacillus plantarum strains isolated from grape must fermentation. Food Microbiol. 2016, 57, 187-194. [CrossRef] [PubMed]

56. Lonvaud-Funel, A. Lactic acid bacteria in the quality improvement and depreciation of wine. Antonie Van Leeuwenhoek 1999, 76, 317-331. [CrossRef] [PubMed]

57. Campbell-Sills, H.; Khoury, M.E.; Gammacurta, M.; Miot-Sertier, C.; Dutilh, L.; Vestner, J.; Capozzi, V.; Sherman, D.; Hubert, C.; Claisse, O.; et al. Two different Oenococcus oeni lineages are associated to either red or white wines in Burgundy: Genomics and metabolomics insights. OENO One 2017, 51, 309. [CrossRef] 
58. Benito, Á.; Calderón, F.; Palomero, F.; Benito, S. Combine Use of Selected Schizosaccharomyces pombe and Lachancea thermotolerans Yeast Strains as an Alternative to the Traditional Malolactic Fermentation in Red Wine Production. Molecules 2015, 20, 9510-9523. [CrossRef] [PubMed]

59. Lorentzen, M.P.G.; Lucas, P.M. Distribution of Oenococcus oeni populations in natural habitats. Appl. Microbiol. Biotechnol. 2019, 103, 2937-2945. [CrossRef] [PubMed]

60. Capozzi, V.; Fragasso, M.; Romaniello, R.; Berbegal, C.; Russo, P.; Spano, G. Spontaneous Food Fermentations and Potential Risks for Human Health. Fermentation 2017, 3, 49. [CrossRef]

61. Spano, G.; Capozzi, V. Food Microbial Biodiversity and Microbes of Protected Origin. Front. Microbiol. 2011, $2,237$.

62. Gobert, A.; Tourdot-Maréchal, R.; Morge, C.; Sparrow, C.; Liu, Y.; Quintanilla-Casas, B.; Vichi, S.; Alexandre, H. Non-Saccharomyces Yeasts Nitrogen Source Preferences: Impact on Sequential Fermentation and Wine Volatile Compounds Profile. Front. Microbiol. 2017, 8, 2175. [CrossRef] [PubMed]

63. Lu, Y.; Chua, J.-Y.; Huang, D.; Lee, P.-R.; Liu, S.-Q. Biotransformation of chemical constituents of durian wine with simultaneous alcoholic fermentation by Torulaspora delbrueckii and malolactic fermentation by Oenococcus oeni. Appl. Microbiol. Biotechnol. 2016, 100, 8877-8888. [CrossRef] [PubMed]

64. Nardi, T.; Panero, L.; Petrozziello, M.; Guaita, M.; Tsolakis, C.; Cassino, C.; Vagnoli, P.; Bosso, A. Managing wine quality using Torulaspora delbrueckii and Oenococcus oeni starters in mixed fermentations of a red Barbera wine. Eur. Food Res. Technol. 2019, 245, 293-307. [CrossRef]

65. Capozzi, V.; Berbegal, C.; Tufariello, M.; Grieco, F.; Spano, G.; Grieco, F. Impact of co-inoculation of Saccharomyces cerevisiae, Hanseniaspora uvarum and Oenococcus oeni autochthonous strains in controlled multi starter grape must fermentations. LWT 2019, 109, 241-249. [CrossRef]

66. Padilla, B.; Zulian, L.; Ferreres, À.; Pastor, R.; Esteve-Zarzoso, B.; Beltran, G.; Mas, A. Sequential Inoculation of Native Non-Saccharomyces and Saccharomyces cerevisiae Strains for Wine Making. Front. Microbiol. 2017, 8, 1293. [CrossRef] [PubMed]

67. Bartowsky, E.J. Oenococcus oeni and malolactic fermentation-Moving into the molecular arena. Aust. J. Grape Wine Res. 2008, 11, 174-187. [CrossRef]

68. Lucio, O.; Pardo, I.; Heras, J.M.; Krieger-Weber, S.; Ferrer, S. Use of starter cultures of Lactobacillus to induce malolactic fermentation in wine. Aust. J. Grape Wine Res. 2017, 23, 15-21. [CrossRef]

69. Renault, P.; Gaillardin, C.; Heslot, H. Product of the Lactococcus lactis gene required for malolactic fermentation is homologous to a family of positive regulators. J. Bacteriol. 1989, 171, 3108-3114. [CrossRef]

70. Bae, S.; Fleet, G.H.; Heard, G.M. Lactic acid bacteria associated with wine grapes from several Australian vineyards. J. Appl. Microbiol. 2006, 100, 712-727. [CrossRef]

71. Kioroglou, D.; LLeixá, J.; Mas, A.; Del Carmen Portillo, M. Massive Sequencing: A New Tool for the Control of Alcoholic Fermentation in Wine? Fermentation 2018, 4, 7. [CrossRef]

72. Wolfe, B.E.; Dutton, R.J. Fermented foods as experimentally tractable microbial ecosystems. Cell 2015, 161, 49-55. [CrossRef] [PubMed]

73. Garofalo, C.; Berbegal, C.; Grieco, F.; Tufariello, M.; Spano, G.; Capozzi, V. Selection of indigenous yeast strains for the production of sparkling wines from native Apulian grape varieties. Int. J. Food Microbiol. 2018, 285, 7-17. [CrossRef] [PubMed]

74. Zhang, J.; Kobert, K.; Flouri, T.; Stamatakis, A. PEAR: A fast and accurate Illumina Paired-End reAd mergeR. Bioinformatics 2014, 30, 614-620. [CrossRef] [PubMed]

75. Caporaso, J.G.; Kuczynski, J.; Stombaugh, J.; Bittinger, K.; Bushman, F.D.; Costello, E.K.; Fierer, N.; Peña, A.G.; Goodrich, J.K.; Gordon, J.I.; et al. QIIME allows analysis of high-throughput community sequencing data. Nat. Methods 2010, 7, 335-336. [CrossRef] [PubMed]

76. Rognes, T.; Flouri, T.; Nichols, B.; Quince, C.; Mahé, F. VSEARCH: A versatile open source tool for metagenomics. Peer] 2016, 4, e2584. [CrossRef] [PubMed]

77. Quast, C.; Pruesse, E.; Yilmaz, P.; Gerken, J.; Schweer, T.; Yarza, P.; Peplies, J.; Glöckner, F.O. The SILVA ribosomal RNA gene database project: Improved data processing and web-based tools. Nucleic Acids Res. 2013, 41, D590-D596. [CrossRef]

78. R: The R Project for Statistical Computing. Available online: https://www.r-project.org/ (accessed on 15 September 2018). 
79. McMurdie, P.J.; Holmes, S. phyloseq: An R Package for Reproducible Interactive Analysis and Graphics of Microbiome Census Data. PLoS ONE 2013, 8, e61217. [CrossRef]

80. Vegan: Community Ecology Package. Ordination methods, Diversity Analysis and Other Functions for Community and Vegetation Ecologists|World Agroforestry Centre. Available online: http://www.worldagroforestry.org/ publication/vegan-community-ecology-package-ordination-methods-diversity-analysis-and-other (accessed on 15 September 2018). 